\title{
Quantity and electricity consumption of plug load equipment on a university campus
}

\author{
Moira Hafer (iD
}

Received: 18 December 2015 / Accepted: 19 December 2016/Published online: 30 December 2016

(C) The Author(s) 2016. This article is published with open access at Springerlink.com

\begin{abstract}
The percent of energy consumed by plug load equipment in commercial buildings is on the rise. Research conducted in the past has included surveying plug load equipment, measuring plug load electricity consumption and equipment operating patterns, and studying plug load reduction solutions in office buildings, but plug load energy use across other building types is poorly understood. A university campus, which houses many building types, presents a unique opportunity to understand plug load profiles across building types. In this study, an equipment inventory was performed in 220 buildings on Stanford University's campus, totaling $8,901,911 \mathrm{ft}^{2}$ of building space and encompassing lab buildings, office buildings, recreation facilities, public space, and service buildings. Within these buildings, 110,529 pieces of plug load equipment were recorded. Energy consumption estimates were developed from published values and used to evaluate the aggregate plug load energy consumption of this equipment by equipment type and by building type. In total, it is estimated that the plug loads from these buildings consume nearly 50 million $\mathrm{kWh}$ per year and comprise $32 \%$ of the electricity consumption of the buildings surveyed. This data can be used to better target energy conservation efforts throughout multiple sectors.
\end{abstract}

\footnotetext{
M. Hafer $(\triangle)$

Department of Sustainability and Energy Management, Stanford University, 327 Bonair Siding, Stanford, CA 94305, USA e-mail: mbhafer@stanford.edu
}

Keywords Plug load · Equipment inventory · Office building $\cdot$ Lab building

\section{Introduction}

Equipment with non-traditional end uses in commercial buildings in the USA consumed over 7 billion MMBtu in 2012, and the energy intensity of these miscellaneous loads is expected to increase by $21.4 \%$ by 2040 (Energy Information Administration 2014). One reason for this projected increase is that current building energy efficiency standards do not cover the majority of this miscellaneous equipment, as they do for equipment with traditional end uses such as lighting and space conditioning. As these traditional end uses become more efficient, the amount of energy that goes towards them decreases as a percent of total building energy consumption, creating a simultaneous rise in the percentage of electricity that is used by other miscellaneous equipment, hereafter deemed "plug loads" in this paper. Moreover, the increased market penetration of electronic products combined with the increased requirement for new electronic products that aid worker productivity in commercial buildings ensures that the electricity consumed by plug loads will continue to increase (Moorefield et al. 2011). It will be important to address this growing area of electricity consumption to support climate change mitigation, grid stability, and energy security, among other environmental concerns.

Twenty percent of the electricity consumption in California's office buildings can be attributed to plug 
loads (Moorefield et al. 2011). Through metering, solutions for reducing plug load energy consumption in office buildings have also been evaluated, such as installing advanced power strips, converting to ENERGY STARß-certified appliances, and/or implementing behavioral campaigns. A combination of savings strategies like this demonstrated a $47 \%$ reduction in associated electricity consumption in one office building (Lobato et al. 2011).

Fewer studies have evaluated the plug load energy consumption of other building types. Black et al. (2012) developed a framework for determining power and energy consumption for medical equipment and miscellaneous loads in hospitals. Additionally, when one healthcare facility was surveyed, plug loads comprised $19 \%$ of its total electricity consumption (Webber et al. 2006). Webber et al. (2006) also evaluated education buildings and large office buildings and estimated that these loads comprised 18 and $11 \%$ of the electricity consumed at these sites, respectively.

Variability in the density of plug load equipment has been shown to be high, even across buildings of the same type and size (Acker et al. 2012). Furthermore, sample sizes have ranged from a single building to 47 sites, but even the larger sample sizes have not been statistically valid enough to represent equipment densities and energy consumption at a state or national level (Moorefield et al. 2011). On the campus of a research institution, which naturally houses numerous building types and varieties of equipment, a thorough understanding of plug load equipment could only be gained through the completion of a comprehensive equipment inventory. While Stanford University's equipment inventory is not necessarily representative of that of other commercial buildings, it is the largest inventory conducted to date to our knowledge, and it can shed light on the types of equipment and associated energy consumption that can be found not only in buildings on other university campuses but also across office buildings, healthcare facilities, and other sectors. Moreover, the findings of this study can inform design for new construction, preventing design teams from overestimating plug loads and, in turn, oversizing cooling systems.

\section{Study overview}

The purpose of this study was to quantify plug load energy consumption on the campus of a research institution in order to inform potential plug load reduction strategies. While Stanford University, like many other entities, has a well-developed understanding of the electricity that goes to traditional end uses, such as hardwired lighting and HVAC systems in its buildings, plug loads manifested the missing piece of the electricity puzzle.

In this study, plug loads are defined as electricity being drawn from any piece of equipment that is plugged into an outlet, categorized into 55 specific types of equipment. This study incorporates the majority of equipment within the three categories in the standardized taxonomy developed by Nordman and Sanchez (2006) (electronics, plug loads within traditional end uses, and miscellaneous loads), which in turn captures the categories utilized in other studies, including office equipment, miscellaneous electric loads (MELs), and information and communication technologies (ICTs), including servers.

Results and analysis are presented here from a comprehensive plug load equipment inventory conducted in summer 2014 throughout 220 buildings, or $8,901,911 \mathrm{ft}^{2}$ of building space across Stanford's campus. The thoroughness of this study allowed Stanford to collect a detailed snapshot of its campus-wide plug load equipment, which has opened the door to identifying underlying trends in equipment densities and energy consumption. Those trends can then be compared across building types both internally and externally to benchmark plug load energy consumption on university campuses and measure variability with other sectors. While this study does not capture measured energy consumption data, it does represent the most thorough inventory of plug load equipment conducted to date, which can lead to informed and data-driven plug load reduction strategies, especially through subsequent metering studies, that will continue to expand our knowledge of plug load equipment energy consumption and reduction in commercial buildings.

\section{Methodology}

The protocol developed for this inventory was very precise in order to consistently and efficiently capture equipment data. Trained student interns used a smartphone application to collect inventory data on 55 types of equipment, along with predetermined attributes. This involved visiting every room in each of the 220 buildings that were inventoried. The final energy 
consumption estimates were applied to all 110,529 pieces of equipment recorded in our central database in order to calculate aggregate energy consumption estimates and begin to identify underlying trends.

\section{Study scope}

The 55 types of equipment included in the inventory were divided into eight overarching categories: Audio/ Video, Computers and Monitors, Gym and Training Equipment, Laundry Equipment, Occupant Comfort, Printers and Scanners, Kitchen and Breakroom, and Lab Equipment. The types of equipment included in each category can be found in Table 6 in the Appendix.

Multiple energy consumption values were developed for each type of equipment based on different equipment attributes, allowing for the most accurate energy consumption estimates possible for each piece of equipment. For example, the attributes for computers were type (laptop or desktop) and brand. Energy consumption estimates were therefore developed separately for laptops and desktops based on their brands (Mac or PC). A list of all attributes and definitions can be found in Table 6 in the Appendix.

Attributes were predetermined and appeared automatically when a piece of equipment was entered into the smartphone application. Some attributes differ from what has been collected in previous studies. For instance, this study categorized printers as "personal printers" and "shared printers." The goal of this division was to identify how many individuals on campus are using a printer assigned only to them compared to individuals who use shared printers within their office spaces. This also allowed for the identification of spaces where both shared printers and personal printers were in use.

It is important to note that the inventory extended past plug loads when considering the resources required for the full effort. The inventory also captured occupancy counts, water fixture data, and environmental health and safety hazards — or "red flags" — such as hazardous material caches, fire hazards, and obstructed egresses. The data gathered within these additional categories was then shared with relevant groups for remediation. Occupancy data, however, was used directly in this study for calculation of equipment densities and energy consumption per occupant. Subsequent occupancy calculations presented in this paper are based on the number of desks per building, as recorded during the inventory.
Site selection

Stanford's criteria for inclusion in this study were oncampus buildings that are served by Stanford's electrical distribution system. A total of 220 buildings, comprising $8,901,911 \mathrm{ft}^{2}$ of building space, were fully inventoried. At Stanford, each building is assigned a building type according to Stanford's building classification system. For this study, some of these building classifications have been combined to better reflect standard commercial building types. Table 1 defines these building types and sizes.

Processes were put in place to access locked rooms, attics, basements, data centers, IT closets, and any other accessible space in each building in order to be as thorough as possible. Building managers supported this effort and commonly walked around with student interns to unlock rooms. Rooms that could not be accessed were logged by interns as "incomplete." In buildings that were considered fully inventoried, $89 \%$ of the rooms were successfully completed. There were also two additional buildings included in the total in which only partial inventories were conducted. These two buildings represent $354,418 \mathrm{ft}^{2}$ of building space together and could not be fully inventoried due to time and scheduling constraints as well as privacy and security issues. Instead, a number of representative rooms were surveyed in each building, and data was extrapolated based on the total number of offices, wet labs, dry labs, kitchens, and breakrooms in each building. The extrapolated equipment data is included in all calculations in this paper.

The inventory spanned $60 \%$ of Stanford's campus. Twenty-six percent of the campus is student and faculty residences, which comprise 4,516,800 $\mathrm{ft}^{2}$ of building space. These spaces were excluded for privacy reasons and because the inventory occurred over the summer when many student residences are vacant. Based on this approach, this study ultimately lends itself to primarily inform the commercial building sector, rather than residential. The remaining $14 \%$ of building space on campus that was not inventoried included buildings under construction or temporarily vacant, patient care buildings, and buildings not served by Stanford utilities. The two buildings that house the campus data centers (approximately $52,397 \mathrm{ft}^{2}$ ) were also not included due to security concerns. Despite these exclusions, this inventory pushed the boundary of typical building surveys, which commonly impose limits based on time, number 
Table 1 Summary of building types included in inventory

\begin{tabular}{|c|c|c|c|c|c|}
\hline Building type & $\begin{array}{l}\text { Number of } \\
\text { buildings }\end{array}$ & $\begin{array}{l}\text { Gross square } \\
\text { feet }\end{array}$ & Occupancy & Rooms & Building classifications included \\
\hline Labs & 42 & $3,258,412$ & 7593 & 6417 & High-intensity lab, low-intensity lab, greenhouse \\
\hline Offices & 90 & $2,008,637$ & 4412 & 5484 & Office, medical office, studio \\
\hline Classroom & 34 & $1,674,265$ & 3232 & 3053 & Classroom \\
\hline Public space & 17 & $1,268,616$ & 971 & 1432 & Auditorium, commons, library, museum \\
\hline $\begin{array}{l}\text { Recreation } \\
\text { facility }\end{array}$ & 13 & 604,664 & 317 & 518 & Recreation facility \\
\hline Service facility & 24 & 87,317 & 120 & 169 & $\begin{array}{l}\text { Shops, service facility, environmental facility, storage, } \\
\text { miscellaneous }\end{array}$ \\
\hline
\end{tabular}

of floors and rooms, and areas deemed inaccessible, especially IT closets. Regardless, Stanford's inventory remained as unobtrusive as possible, which was aided by the smartphone application used for data collection, allowing interns to enter equipment data in each room in a matter of minutes, so as not to disrupt anyone's work for too long.

Site surveys

A total of 12 student interns conducted the equipment inventory over the course of 5 months between April and September of 2014. In total, interns worked approximately $2760 \mathrm{~h}$, with approximately an additional $300 \mathrm{~h}$ of staff time during those 5 months devoted to scheduling the inventory in each building, coordinating with building managers, and training and advising interns.

To ensure consistency in data entry, interns followed a well-developed data collection protocol. Interns were able to inventory building space at an average rate of $3200 \mathrm{ft}^{2}$ per hour. Stanford's Land, Buildings, and Real Estate application systems group developed the smartphone application used for data collection, which combined electronic versions of all of Stanford's building floor plans, uploaded through ArcGIS, with a web form that could be accessed via the ArcGIS smartphone application with an Oracle database backend for each individual room. The web form contained drop-down lists of the equipment categories and equipment types and automatically populated attributes based on the equipment type selected. Once each piece of equipment with its relevant attributes was added to the web form for that room, interns could mark the room as complete, which would change the color of the room from red to green on the floor plan within the ArcGIS application, allowing for easy tracking of progress. Equipment data by room was stored in an online database and could be easily downloaded to Microsoft Excel from the Oracle database through the application. This innovative approach to equipment data collection not only allowed for efficiency gains, but it also improved accuracy, data accessibility, and security.

\section{Data analysis methodology}

At the conclusion of the inventory, the equipment data was aggregated and analyzed to quantify plug load electricity consumption. First, unit energy consumption (UEC) estimates were developed and applied to each piece of equipment based on its attributes, as shown in Table 6 in the Appendix. Table 6 also displays the key assumptions that factored into the development of each UEC value. Each value was developed in one of two ways: either the energy consumption values were obtained directly, or the power consumption values were obtained and combined with assumptions regarding how much time, on average, devices of that type at Stanford would spend in the on, idle, standby, and off states per day. The specific amounts of time that each device type was assumed to be in each power state in both hours per day and days per year (when less than 365) are listed in Table 6. The four power states, as conceptualized in this study, are defined as follows: "on" represents a device that is active and/or in use; "idle" represents a device that is turned on but not active; "standby" represents a device that is either turned on and in its lowest power mode or turned off but still consuming power; and "off" represents a device that is turned off and consuming no power. Assumptions regarding time spent in each power state 
were largely drawn from occupant feedback during initial pilots of the study in office, gym, and lab buildings that were conducted in late 2013 and early 2014. These assumptions are therefore largely qualitative, and future work could focus on improving these estimates by collecting more robust data about time spent in each power state, especially for highly prevalent device types.

Power and energy consumption values were obtained either from measurements or published data. In the case of published data, there were several types of sources. First, some values were taken from online databases of measurements compiled by organizations including Lawrence Berkeley National Lab, Labs 21, and ENERGY STAR. Other values were derived from those used and/or discussed in prior research, including the research cited in this paper as well as previous studies conducted at Stanford or by other organizations, such as the Office of Energy Efficiency and Renewable Energy and the California Energy Commission. Finally, some values were drawn from manufacturer specifications. Table 6 shows the values pulled from each of these locations as applicable, especially for equipment types for which energy consumption values were used directly. In cases where multiple published values were identified and there was not a single value that clearly applied to the equipment type and attribute in question, an average of the published values was developed, which is indicated in Table 6 with the notation "Average of published values." In some cases, weighted averages were also used, as noted in Table 6.

There was a maximum of three attributes per equipment type, and some equipment types were not assigned any attributes. There were also some cases in which the attribute collected did not actually inform the UEC value used, which typically occurred if there were a multitude of options for a single attribute, such as brand or temperature, or if the attribute was collected for another purpose and was therefore irrelevant to the UEC. These cases are denoted with an asterisk in Table 6. Finally, attributes were not input if the attribute could not be discerned. For example, if the bulb type was not apparent in a desk lamp, the attribute would be left blank. There were also a minor number of instances where attributes were not saved due to database errors. In any instances where attributes were blank, an average of the UEC values across the equipment type was developed and applied as the UEC value for each piece of equipment with a blank attribute.
Based on the specific UEC values generated, all equipment quantities and energy consumption data were aggregated to determine campus-wide totals, as well as totals by equipment type and building. Total energy consumption (TEC) was calculated for each equipment type according to the equation below, where

$\mathrm{N}_{1} \quad$ quantity of equipment with attribute 1

$\mathrm{UEC}_{1}$ unit energy consumption of equipment with attribute 1

$\mathrm{N}_{2}$ quantity of equipment with attribute 2

$\mathrm{UEC}_{2}$ unit energy consumption of equipment with attribute 2

$\mathrm{N}_{3} \quad$ quantity of equipment with attribute 3

$\mathrm{UEC}_{3}$ unit energy consumption of equipment with attribute 3

$$
\begin{aligned}
\mathrm{TEC}= & \left(\mathrm{N}_{1} \times \mathrm{UEC}_{1}\right)+\left(\mathrm{N}_{2} \times \mathrm{UEC}_{2}\right) \\
& +\left(\mathrm{N}_{3} \times \mathrm{UEC}_{3}\right)
\end{aligned}
$$

The above equation changes accordingly based on the number of attributes associated with each equipment type. TEC by equipment type is listed in Table 7 and illustrated in Fig. 9 in the Appendix.

\section{Limitations of methodology}

The advantage of conducting this study on a university campus was that some centralized oversight of buildings does exist, which facilitated the process of conducting a large-scale, 220-building inventory of 55 equipment types. However, one limitation was that uncommon plug loads (not captured by the 55 equipment types) were not included in the inventory. This was especially true in labs where specialized equipment is prevalent. Thus, the plug loads discussed in this paper do not represent the entirety of equipment in the 220 buildings that were inventoried. Furthermore, because many buildings, such as student residences, were also not inventoried, the plug loads discussed in this paper also do not fully represent Stanford University's complete plug load profile, even within the 55 equipment types included in this study.

Also, because the scope of the inventory was so large, and because having a thorough set of equipment data was a priority, metering plug load equipment was 
not feasible during this study. Metering should be conducted as part of subsequent field testing of plug load equipment and potential reduction opportunities. Based on the results of this study, metering can be focused on the most prevalent and/or highest energy-consuming types of equipment and should use principles from previous studies on appropriate sample sizes, sampling intervals, and duration of metering, such as those listed in Lanzisera et al. (2013).

Human error has also been shown to factor into building surveys (Webber et al. 2006). While interns underwent a rigorous training process, there remains a high likelihood that some equipment data was recorded incorrectly. For instance, one common mistake that was noted during staff checks of equipment data was that covered compact fluorescent light bulbs were often recorded as incandescent light bulbs. However, any human errors that could have been made during the data entry process itself were likely minimized due to use of the smartphone application.

It is also important to note that this inventory represents a single snapshot of the equipment on Stanford's campus. This snapshot was taken during the summer months when some buildings may not have been functioning as they would throughout the rest of the year. Additionally, seasonal variations were not captured, although Acker et al. (2012) found that seasonal variation in equipment densities was not significant. Follow-up surveys at Stanford would help identify trends in equipment procurement and removal over time, which could be valuable data on a university campus where much of the population is transient, especially if future surveys were to include student plug loads.

Finally, because assumptions were used to calculate the UEC for each piece of equipment, there will be error in the energy consumption values used in this study. For equipment types whose consumption is entirely dependent on how much time a device spends in use or in other power states, the margin of error depends most heavily on how often users actually use the device compared to any usage assumptions that factor into its assigned UEC estimate. Equipment types that are heavily affected by assumptions of this nature include space heaters, personal computers, TVs, coffee makers, and hot plates, to name a few. On the other hand, equipment types that stay on all the time are less affected by usagebased assumptions; these equipment types include common refrigerators, lab refrigerators and freezers, and ice machines, among others.
Moreover, the UEC estimates are based only on the attributes that were recorded during this study and therefore do not take all energy consumption factors for all pieces of equipment into account. Generally, there will be a larger margin of error for equipment types with no attributes recorded in this study, while the margin of error may be smaller for equipment types with multiple attributes recorded in this study. Overall, the attributes for equipment types that are the most complex and/or have the widest spectra of energy consumption will be the least granular and will therefore have the highest margin of error. This error margin compounds across each unit of each type of equipment, so the most prevalent types of equipment on campus are also likely to have the highest potential for error when considering the TEC of that equipment type. Ultimately, the value of this inventory is the thoroughness of the study scope and building surveys, which allowed Stanford to identify clear trends in both equipment densities and energy consumption campus-wide and by building type; many of these trends are not predicated upon the utmost precision in energy consumption values.

\section{Results and discussion}

The results of this study were first aggregated by equipment type and category to determine Stanford's approximate plug load profile and identify underlying trends. The results of this survey are presented below by equipment type and building type. At the equipment level, equipment density, estimated energy consumption, and key savings opportunities are summarized by equipment category, with discussion of the primary equipment types that factor into each category. At the building level, results are presented by type of building in order to highlight underlying trends within and across building types to demonstrate the relevance of this inventory to various sectors.

\section{Summary of results}

In total, Stanford collected 132,964 data points during this inventory, 110,529 of which pertained to plug load equipment. The other 22,435 data points pertained to environmental health and safety "red 
flags," water fixtures, and occupancy counts. Based on the gross square footage of building space inventoried and the building occupancy numbers collected during the inventory, this study found that Stanford has an overall plug load equipment density of 12.4 pieces of equipment per thousand square feet and 6.6 pieces of equipment per building occupant, excluding pieces of equipment that did not fall into the 55 types of equipment that were inventoried. Table 2 summarizes the quantities and densities of equipment within these 55 equipment types on campus by category. This information can be found at a granular level for each type of equipment in Table 7 in the Appendix, in addition to TEC by equipment type.

Stanford's results for number of plug load devices per occupant (6.6) remain fairly consistent with the data from previous studies. Webber et al. (2006) studied small, medium, and large offices, healthcare facilities, and education facilities and found an average of 8.9 devices per occupant, and Acker et al. (2012) looked exclusively at commercial office buildings of different sizes and found average equipment density to be 6.7 devices per occupant.

Interestingly, the number of devices per square foot on Stanford's campus is less than half the figures found in other studies. For example, Moorefield et al. (2011) showed about 30 devices per thousand square feet in commercial buildings. One factor driving this is that a university campus has more open building space (with few to no items plugged in) than standard commercial buildings, which is supported by the data for Public Spaces and Recreation Facilities depicted in Fig. 1. In addition, the square footage used in this study represents the gross square footage of all 220 buildings included in this study, not all of which contains occupants and/or equipment. In other studies, the square footage is often represented as just the section or floor of a building that was inventoried, so the figures only capture the areas that contain both occupants and equipment and thus result in larger device to square foot ratios.

Figure 1 shows Stanford's equipment density per thousand square feet by both equipment type and building type. Labs have the highest average equipment density at a total of 17.2 devices per thousand square feet, followed by offices at 13.9 , while recreation facilities have the lowest equipment density at a total of 4.5 devices per thousand square feet. Of course, the density of lab equipment in lab spaces is much higher than in any other type of building at approximately 4.6 devices per thousand square feet. This additional equipment is the primary driver of increased equipment density in lab buildings. It is noteworthy that the Computers and Monitors category, including personal computers, monitors, servers, and other computing equipment, is the most prevalent category of equipment in all building types, including lab buildings. In fact, the density of computing and networking equipment in labs and offices is the same, at 6.8 devices per thousand square feet. Similarly, the number of computing and networking devices per occupant remains fairly similar among labs and offices, at 3.1 and 3.0 devices per occupant, respectively. The most prevalent types of equipment within this category-and overall-are personal

Table 2 Equipment quantity and density by category

\begin{tabular}{|c|c|c|c|c|c|}
\hline Equipment type & $\begin{array}{l}\text { Total } \\
\text { quantity }\end{array}$ & $\begin{array}{l}\text { Percent of total } \\
\text { equipment Inventoried }\end{array}$ & $\begin{array}{l}\text { Density } \\
\text { (units/ thousand } \mathrm{ft}^{2} \text { ) }\end{array}$ & $\begin{array}{l}\text { Density } \\
\text { (units/occupant) }\end{array}$ & $\begin{array}{l}\text { Density } \\
\text { (units/room) }\end{array}$ \\
\hline Computers and monitors & 48,112 & $44 \%$ & 5.40 & 2.89 & 2.82 \\
\hline Audio/video & 17,170 & $16 \%$ & 1.93 & 1.03 & 1.01 \\
\hline Occupant comfort & 16,534 & $15 \%$ & 1.86 & 0.99 & 0.97 \\
\hline Lab equipment & 15,123 & $14 \%$ & 1.70 & 0.91 & 0.89 \\
\hline Printers and scanners & 7192 & $7 \%$ & 0.81 & 0.43 & 0.42 \\
\hline Kitchen and breakroom & 6089 & $6 \%$ & 0.68 & 0.37 & 0.36 \\
\hline Gym and training equipment & 265 & $0.2 \%$ & 0.03 & 0.02 & 0.02 \\
\hline Laundry equipment & 44 & $0.04 \%$ & 0.005 & 0.003 & 0.003 \\
\hline Grand total & 110,529 & $100 \%$ & 12.42 & 6.64 & 6.47 \\
\hline
\end{tabular}




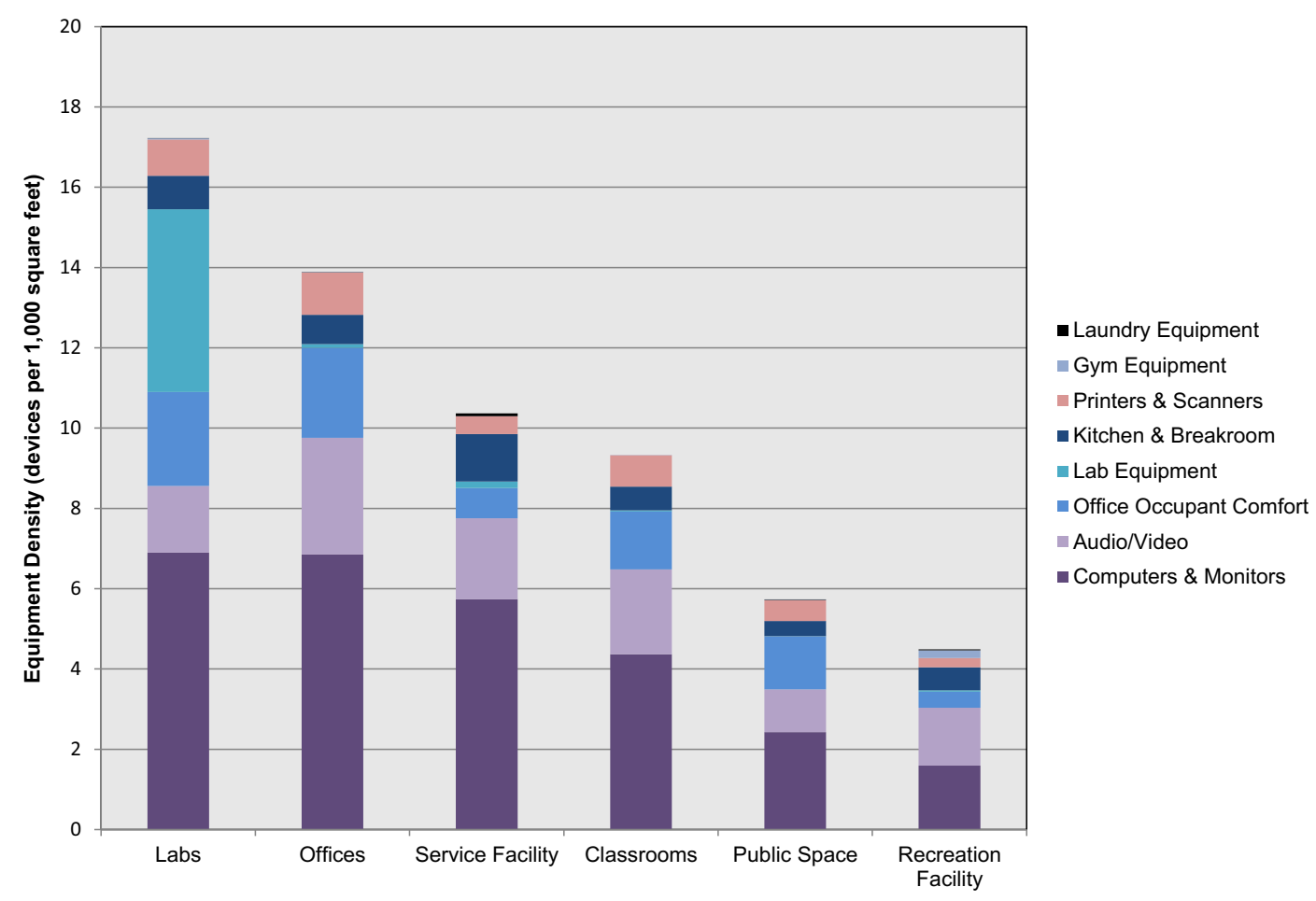

Fig. 1 Equipment density by category and building type

computers and LCD monitors, which have overall equipment densities of 2.3 and 2.1 devices per thousand square feet and 1.2 and 1.1 devices per occupant, respectively. These findings are further illustrated in Fig. 2, which shows the top 11 most prevalent types of equipment on campus. These 11 equipment types together comprise $72 \%$ of the total equipment present on campus.

The estimated energy consumed by the equipment recorded in Stanford's inventory totals an estimated 48,214,090 kWh per year. This electricity consumption

Fig. 2 Quantity of equipment by equipment type

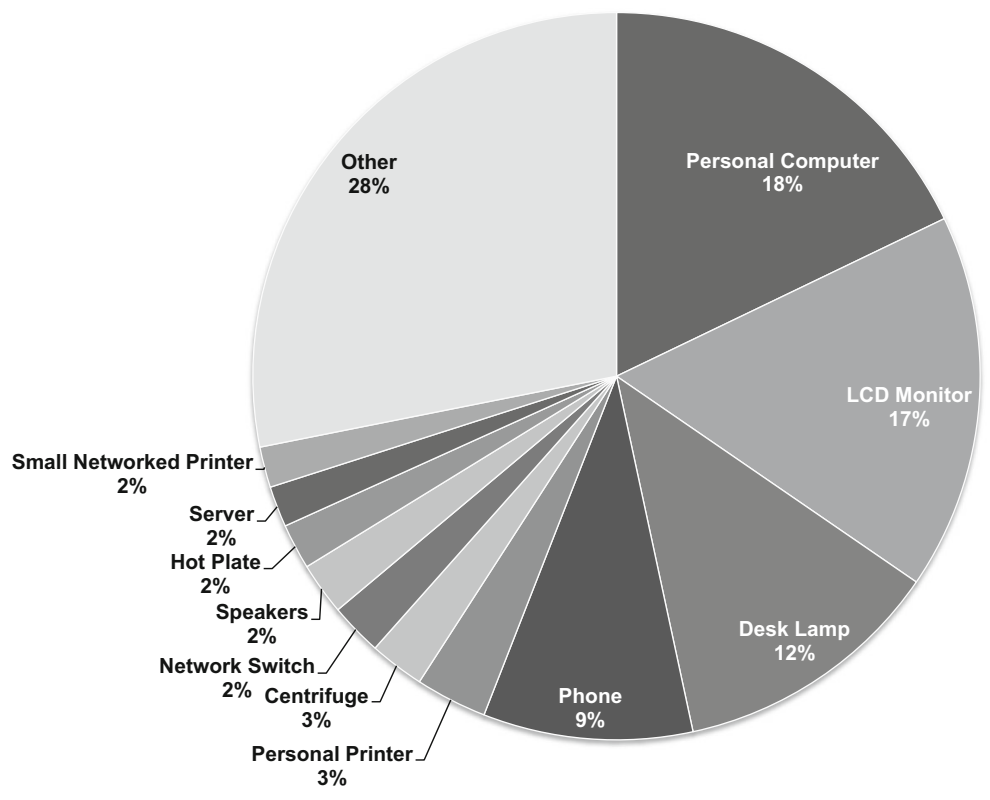


comprises $32 \%$ of the energy use of the 220 buildings included in the inventory.

Table 3 summarizes TEC and other energy consumption metrics by equipment category. Overall, plug load energy use intensity is estimated to be $5.42 \mathrm{kWh}$ per square foot per year. It is difficult to draw a direct comparison to previous studies for overall energy intensity, since this study includes lab equipment and IT equipment, whereas previous studies have not. Estimated TEC by equipment type is listed in Table 7 in the Appendix, which highlights the equipment types that consume the most energy on Stanford's campus and reveals the entire energy consumption spectrum for all 55 types of equipment included in this study.

Results by equipment type

To better understand the driving factors behind the quantity and energy consumption of the equipment within each category, it is helpful to delve into the results for specific equipment types, which are presented below by equipment category.

\section{Lab equipment}

Lab equipment comprises $50 \%$ of the total estimated plug load energy consumption on Stanford's campus, which equates to $16 \%$ of the electricity consumption of the 220 buildings inventoried and $71 \%$ of total plug load energy use in lab buildings. Figure 3 shows the expected breakdown of lab equipment energy consumption by equipment type. As noted previously, there are many types of specialized lab equipment that are not included in these totals since they were not included in the inventory.

Lab freezers are estimated to consume $7,705,669 \mathrm{kWh}$ per year, which equates to nearly one third of total lab equipment energy consumption and makes lab freezers the second highest plug load consumer on campus, behind servers. A total of 1520 lab freezers were inventoried, and these alone are estimated to consume $16 \%$ of the total plug load energy consumption captured in this study. The temperature and size of each lab freezer were recorded as attributes during the inventory. Altogether, there were 847 standard lab freezers, which are typically set to a temperature of $-20{ }^{\circ} \mathrm{C}$. Of these, 315 were under-counter models and 528 were full-sized. Additionally, there were 515 ultralow temperature (ULT) lab freezers on campus, all of which were full-sized and typically set to $-80^{\circ} \mathrm{C}$. Within the $3,258,412 \mathrm{ft}^{2}$ of lab building space, there is one ULT freezer for every $2222 \mathrm{ft}^{2}$. With each ULT consuming approximately as much energy per year as a single family home, and with energy savings opportunities such as reducing the temperature of the freezer or purchasing an efficient model, this equipment likely presents a viable opportunity for lab equipment energy savings.

Incubators and water baths were estimated to be the next highest-consuming types of lab equipment and the 3rd and 4th highest energy consumers overall, respectively. To date, little research has been done in the field on the energy consumption and savings potential of incubators, so this should be an area of continued study. Moreover, one important component of these equipment types is that they often remain turned on all the time, but

Table 3 Total energy consumption by equipment type

\begin{tabular}{|c|c|c|c|c|}
\hline Equipment type & $\begin{array}{l}\text { Total energy } \\
\text { consumption } \\
(\mathrm{kWh} / \text { year) }\end{array}$ & $\begin{array}{l}\text { Percent energy } \\
\text { consumption } \\
\text { of plug load total }\end{array}$ & $\begin{array}{l}\text { Plug load energy } \\
\text { use intensity } \\
\left(\mathrm{kWh} / \mathrm{ft}^{2} / \text { year }\right)\end{array}$ & $\begin{array}{l}\text { Plug load energy } \\
\text { per occupant } \\
\left(\mathrm{kWh} / \mathrm{ft}^{2} / \text { person }\right)\end{array}$ \\
\hline Lab equipment & $23,955,761$ & $50 \%$ & 2.69 & 1439 \\
\hline Computers and monitors & $17,261,798$ & $36 \%$ & 1.94 & 1037 \\
\hline Kitchen and breakroom & $2,306,695$ & $5 \%$ & 0.26 & 139 \\
\hline Occupant comfort & $1,625,419$ & $3 \%$ & 0.18 & 98 \\
\hline Printers and scanners & $1,478,357$ & $3 \%$ & 0.17 & 89 \\
\hline Audio/video & $1,046,246$ & $2 \%$ & 0.12 & 63 \\
\hline Gym and training equipment & 510,943 & $1 \%$ & 0.06 & 31 \\
\hline Laundry equipment & 28,871 & $0 \%$ & 0.00 & 2 \\
\hline Grand total & $48,214,090$ & $100 \%$ & 5.42 & 2895 \\
\hline
\end{tabular}


Fig. 3 Lab equipment energy consumption by type

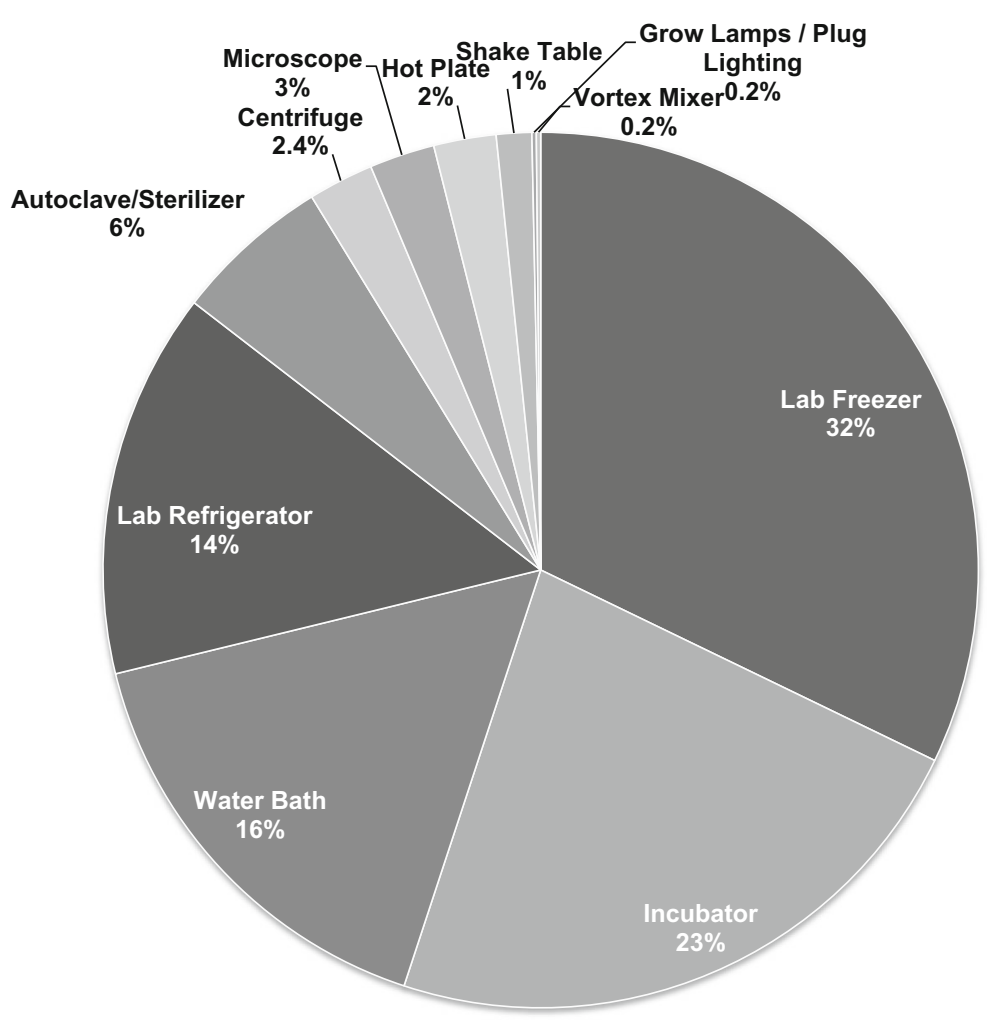

they could be powered down when not in use. This is also true for centrifuges, shake tables, hot plates, microscopes, and vortex mixers. To demonstrate the savings potential of fully shutting off this equipment when not in use, if we were to assume that $25 \%$ of the devices within each of these equipment types at Stanford transitioned from remaining in their respective "on" or "idle" states all the time to being in the "off" power state $12 \mathrm{~h}$ per day, the savings would equate to an estimated $758,288 \mathrm{kWh}$ per year, or approximately $2 \%$ of the plug load energy consumption captured in this study, using the same energy consumption values.

\section{Computers and monitors}

A total of 20,117 personal computers were inventoried, along with 18,803 LCD monitors. An additional 402 cathode ray tube (CRT) monitors were also recorded. This brings the number for both personal computers and monitors separately to 1.2 per occupant. Previous studies have shown computer density to range from 0.53 to 2.18 per employee (Webber et al. 2006; Acker et al. 2012), so the number of computers in Stanford's buildings seems consistent with prior findings. The most popular computer brand was Dell (43\%), followed by Apple (37\%) and Lenovo (7\%) and the remainder divided between other brands.

Of the total desktops and laptops recorded, 69\% were desktops and $31 \%$ were laptops. Additionally, there were 500 docking stations recorded for which a laptop was not present, so it is safe to assume that at least an additional 500 laptops are being used on campus in the buildings that were inventoried. However, laptop chargers were not included separately in the inventory because of their minute power draw, so it is likely that some computers that were not present at the time of the inventory and that use basic chargers rather than docking stations have been overlooked. Finally, because student residences were not included in this study, the majority of the personal computers that were inventoried are used by faculty and staff, although any personal laptops that belonged to students working in the inventoried buildings at the time of the inventory were captured in this data. All other student laptops were not captured.

All of the equipment within the Computers and Monitors category is estimated to comprise $36 \%$ of the plug load electricity consumption captured in this study, 
which equates to $11 \%$ of total electricity consumption in the 220 buildings inventoried. Of course, computers and monitors are prevalent in all types of buildings - as supported by this study's density calculations - but the estimated energy use intensity of these devices across various building types varies dramatically, with energy use intensity in office spaces at $3.64 \mathrm{kWh} / \mathrm{ft}^{2} /$ year, in labs at $2.16 \mathrm{kWh} / \mathrm{ft}^{2} /$ year, and on the low end in both recreation facilities and public spaces at $0.49 \mathrm{kWh} / \mathrm{ft}^{2}$ / year. The biggest reason for this varying energy use intensity for computers and monitors among building types is the presence of IT closets and data centers.

Figure 4 shows the breakdown by energy consumption of equipment types within the Computers and Monitors category. Despite the high quantities of personal computers and monitors present on campus, they are only expected to consume 16 and $7 \%$ of the total electricity consumption of the equipment in the Computers and Monitors category, respectively.

In contrast, servers alone are estimated to consume $60 \%$ of the energy consumption within the Computers and Monitors category, which totals $10,399,486 \mathrm{kWh}$ per year among the 1690 servers recorded in this study. As the single highest plug load energy consumer on campus, estimated server consumption equals $22 \%$ of the total plug load

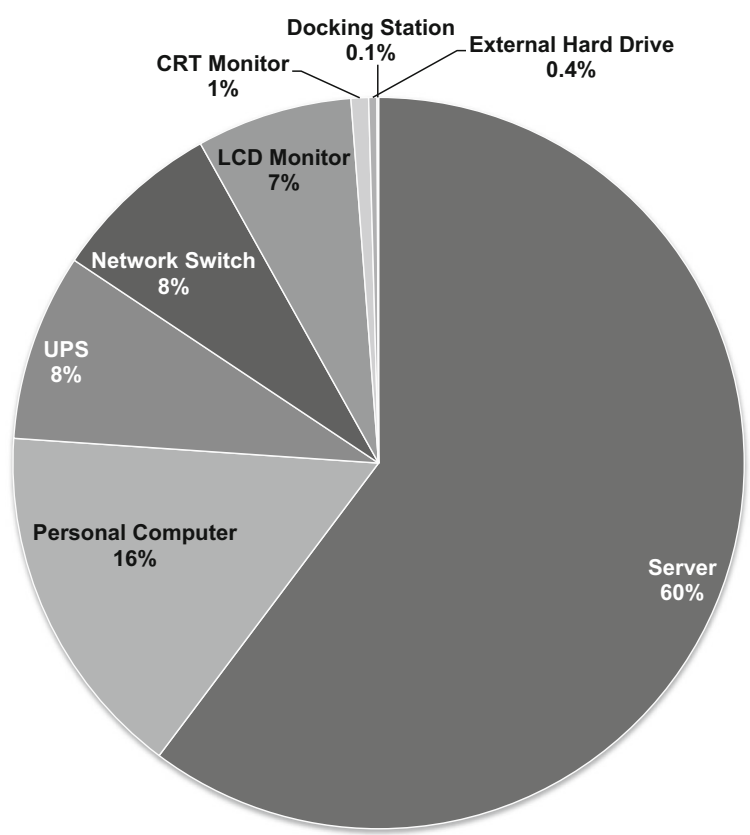

Fig. 4 Computer and monitor equipment energy consumption by type electricity consumption captured in this study. Moreover, many of these servers were found in IT closets without efficient cooling systems, which substantially increases the amount of energy needed to keep servers operating.

Many physical servers have a utilization rate of less than 5\% (Lobato et al. 2011). Through virtualization, all of these physical servers can be consolidated to reach much higher utilization rates while reducing the amount of hardware that needs to be powered, which in turn reduces electricity and maintenance costs (Kamilaris et al. 2013). Lobato et al. (2011) showed that one office facility was able to consolidate a series of 1 and $4 \mathrm{U}$ servers with under $5 \%$ utilization into a $10-\mathrm{U}$ blade server chassis that holds up to 16 individual servers that each have the capacity for approximately 20 virtualized servers. These blade servers require a maximum of six UPSs and ten cooling fans, which is also a significant reduction from the amount of power and cooling necessary for individual 1 and $4-U$ servers. For reference, applying this same setup to Stanford's campus and using the energy consumption estimates developed for this study would allow for savings of approximately 3.8 million $\mathrm{kWh}$ per year at Stanford, which equates to $8 \%$ of the plug load energy consumption captured in this study.

There were also 2631 network switches and 1416 uninterruptible power supplies recorded in this study. The number of network switches on campus is consistent with prior research, but more information needs to be collected on the types and purposes of switches at Stanford in order to inform potential savings opportunities, if any. For instance, Lanzisera et al. (2012) found a total of 450 pieces of managed network equipment and 1500 unmanaged desktop switches in a university case study. Lanzisera et al. (2012) also noted that overall energy use increases in the USA from switching products is likely to concentrate on cable devices, DSL devices, fiber to the building devices, and Ethernet switches. If future work at Stanford were able to categorize the switches recorded in this study, the campus may be able to avoid unnecessary increases in energy use from these categories of network switches.

Substantial research exists on the importance of power management strategies for computers, monitors, and printing equipment. Kawamoto et al. 
(2002) estimate that complete saturation of power management in the USA has the potential to save 47 TWh per year, with an additional 7 TWh per year of potential savings through complete shutdown at night. Pixley and Ross (2014) report that in a university setting, $45 \%$ of participants report leaving their computers turned on at least $50 \%$ of the times that they are away, while $55 \%$ of participants report this activity less than $50 \%$ of the time. Pixley and Ross (2014) also conclude that user behavior plays an integral role in computer energy savings. Power management strategies can also apply to large networked copier/printers, of which there were 245 recorded in this study. Other potential strategies for savings include upgrading older, less efficient CRT monitors; there were 402 CRT monitors recorded in this study. Finally, converting from desktops to laptops is also a potential energy savings strategy, as discussed by Kamilaris et al. (2013). This research, combined with the data presented in this study regarding the number of computers on a university campus, demonstrate that there may be potential for each of these strategies to lead to significant energy savings on a university campus. Comparing and contrasting these strategies, especially using metered data, could be the focus of future work.

\section{Kitchen and breakroom}

Kitchen and breakroom equipment comprises $6 \%$ of the total equipment on campus and an estimated $5 \%$ of the plug load electricity consumption estimated in this study. The entire breakdown of electricity consumption among kitchen and breakroom equipment is depicted in Fig. 5.

There are 919 common refrigerators on campus, which equals one refrigerator for every 18 building occupants. In addition, there were 1277 personal refrigerators recorded in this study, more than doubling the total number of refrigerators per occupant. Ten percent of common refrigerators were specifically noted as older models during the inventory, as defined in Table 6 in the Appendix.

A total of 1022 coffee makers were recorded in the inventory, divided into three categories: singlecup coffee makers, single-pot coffee makers, and multi-pot coffee makers. Of these, the single-cup coffee makers were the most prevalent on campus
Fig. 5 Kitchen and breakroom equipment energy consumption by type

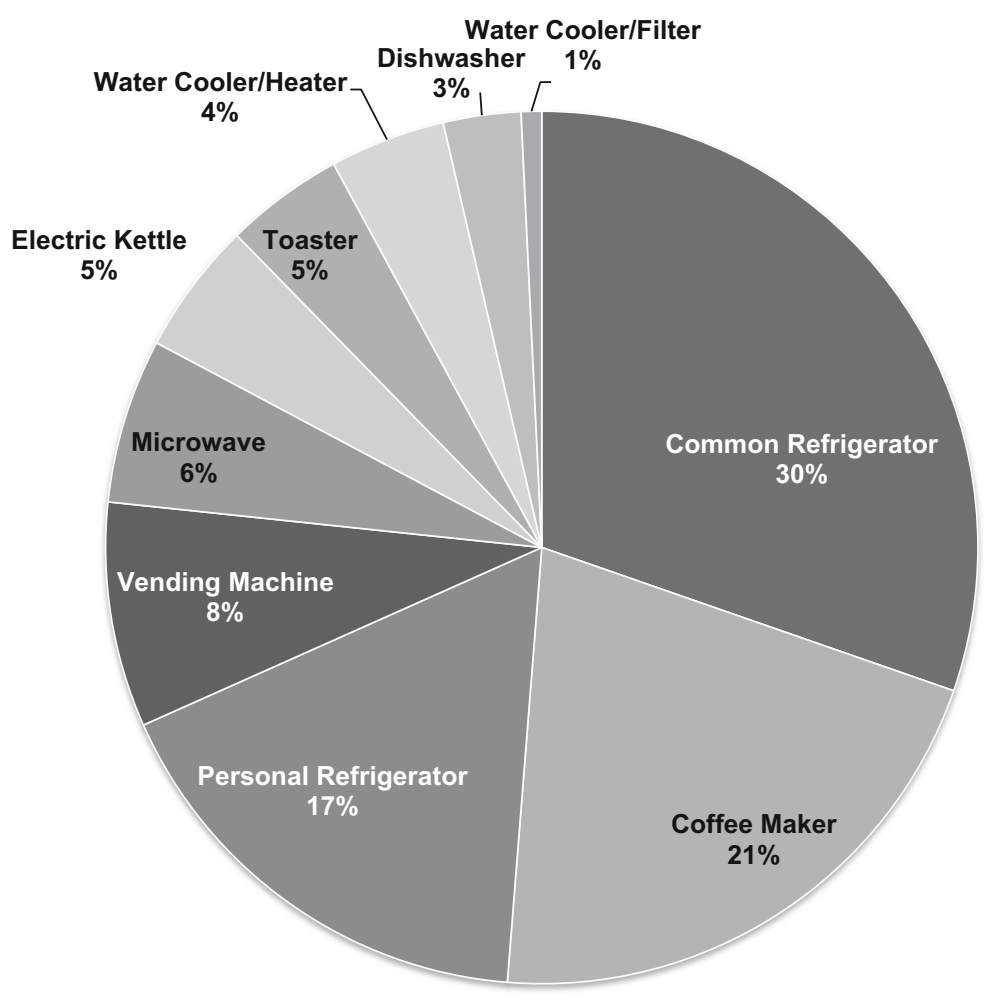


at 483 units, closely followed by the single-pot coffee makers at 421 units and then the multi-pot coffee makers at 109 units. However, multi-pot coffee makers were estimated to consume $119,137 \mathrm{kWh}$ per year, whereas single-cup coffee makers consume only $51,895 \mathrm{kWh}$ per year, despite being over four times more prevalent. Industrial coffee makers can use as much electricity as a standard refrigerator over the course of a year, and there is high variability in coffee maker power levels, with some reaching a low power level for most of the day to keep coffee warm, while others continually cycle between high and low power all day (Moorefield et al. 2011). Especially for models that consistently cycle between high and low power, installing a programmable timer to shut the device off at night could leave to significant energy savings. The same is also true for water coolers, 486 of which were recorded in this study with an estimated TEC of $98,785 \mathrm{kWh}$ per year. In these cases, the use of existing, inexpensive, off-the-shelf technologies could provide a viable savings option and should be further explored, especially in a university setting.

Finally, a total of 81 vending machines were recorded in Stanford's inventory, which are estimated to consume $192,374 \mathrm{kWh}$ per year altogether. The attribute collected for vending machines was the presence of an associated vending miser, which is estimated to save $1000 \mathrm{kWh}$ per machine per year (Lewis et al. 2006). Fifty-three of the vending machines recorded in this study did not have vending misers, which is a clear opportunity for energy savings. Lewis et al. (2006) also discuss other energy savings strategies for vending machines, including converting to ENERGY STAR-certified vending machines, implementing onboard software controls, and de-lamping the front panel or programming lights to turn off on nights and weekends. Many of these strategies may apply to vending machines at Stanford and at other universities, and future work could focus on comparing and contrasting these strategies as well.

\section{Occupant comfort}

Four types of equipment are included in the Occupant Comfort category: desk lamps, space heaters, air conditioning units, and fans. The energy use intensity of these devices stays fairly consistent across building types, with an estimated range of $0.12 \mathrm{kWh}$ per square foot per year of energy consumption in public spaces to $0.24 \mathrm{kWh}$ per square foot per year in lab buildings. The inventory recorded a total of 955 space heaters (approximately one space heater for every 17 building occupants), which in total are estimated to consume $517,634 \mathrm{kWh}$ per year. Space heater energy consumption depends heavily on usage patterns, so the level of uncertainty in this estimate is relatively high. Thus, more research should be conducted on space heater usage patterns before recommending specific solutions for reducing space heater energy consumption.

\section{Printers and Scanners}

Equipment within the Printers and Scanners category comprises $3 \%$ of the total plug load energy consumption captured in this study. For the purposes of this study, printers were divided into three categories: small networked printers, large networked copier/printers, and personal printers. The count and estimated energy consumption of printers in this study by type is depicted in Fig. 6 .

Personal printers were defined as any printer used by only one person; this equipment type comprises primarily small inkjet printers, but printers of any kind could be included in this equipment type if they were used by only one individual. In this study, $76 \%$ of the personal printers captured were HP models. In contrast, small networked printers were defined as any standard-sized printer that is shared among building occupants; within this equipment type, there is more variation between laser and inkjet models, although Moorefield et al. (2011) showed that laser-networked printers outnumber inkjet-networked printers in office buildings by a factor of about 3 to 1 . Overall, $73 \%$ of the small networked printers at Stanford were HP models. Finally, large networked copier/printers are defined as any floor-mounted printing device. These primarily use laser technology and often have additional functionality, such as copying, scanning, and faxing. There is more diversity among the common brands of these devices, with $34 \%$ recorded as Canon models, 26\% Xerox, and 14\% HP. In other building surveys, large networked copier/printers are often referred to as multi-function devices (MFDs). 


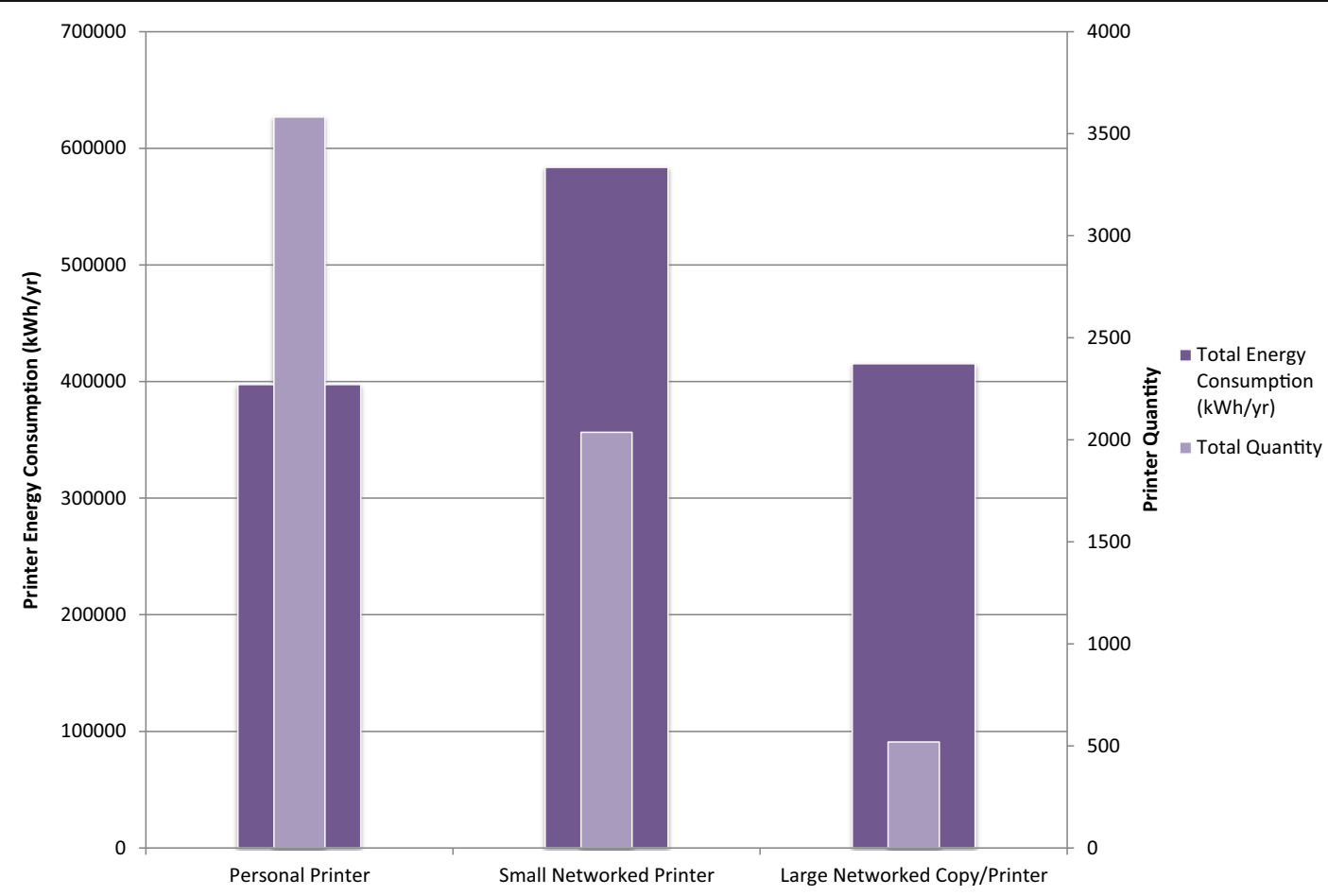

Fig. 6 Printer quantity and energy consumption by printer type

The total number of printers per occupant remains fairly consistent across building types, between 0.32 printers per person in both labs and service facilities and 0.5 printers per person in public spaces. Figure 7 captures printer density per occupant by building type and by printer type. Office buildings have a fairly high printer density at 0.43 per occupant as well as the highest density of personal printers at 0.26 per occupant (one for approximately every four people). On the other hand, the presence of small networked printers is lower than average in office buildings at 0.11 , or one small networked printer for every nine people, suggesting that personal printers may replace shared printers in some spaces rather than supplement them. Finally, public spaces have the highest printer density per occupant overall and among the majority of printer types. One reason for this may be that public spaces often have small administrative units with only a few occupants, but those occupants still require the same printing functionality as occupants in larger administrative units. This suggests that one energy-saving strategy is actually to group occupants in larger office spaces, which would allow for condensing shared devices like printers. This has been shown to be an effective energy in other studies, such as Lobato et al. (2011).

Other devices in the Printers and Scanners category include scanners, fax machines, and plotters. Together, these devices are estimated to consume $81,951 \mathrm{kWh}$ per year. These items often have redundant functionality to new MFDs (which were recorded as large networked copier/printers in this inventory), but there are still a total of 1053 of these various devices on campus. Webber et al. (2006) suggested that increased procurement of multi-function devices does not necessarily correlate with a reduction in equipment like fax machines, which is supported by these findings.

\section{Results by building type}

Table 4 illustrates relevant equipment quantity, density, energy consumption, and energy intensity figures by building type. It is worth noting that due to a few cases of data inadvertently being captured without an associated building, the totals by building type do not align perfectly with the totals by equipment type. 


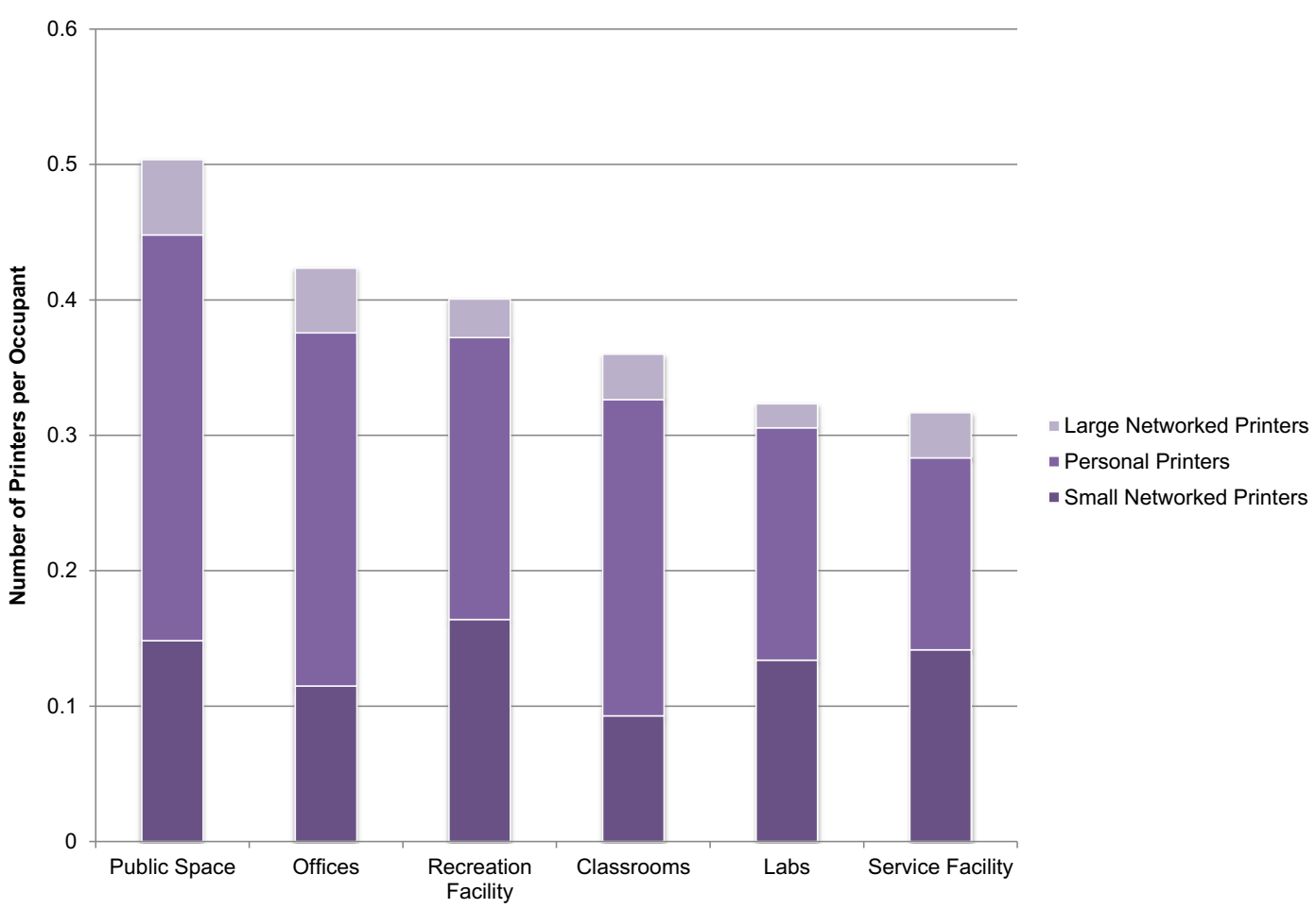

Fig. 7 Printer density by printer type and building type

Lab buildings and office buildings together consume $89 \%$ of the estimated plug load electricity consumption in this study. However, plug loads in lab buildings are ultimately much more significant than those in office buildings; labs consume an estimated $69 \%$ of the total plug load electricity, while offices are projected to consume only $20 \%$. The next highest building type is classrooms at an estimated $6 \%$ of total plug load electricity consumption, which have a similar plug load profile to offices but are fewer in number. Lab buildings also contain the highest quantities of equipment at $51 \%$ compared to offices which contain only $25 \%$ of the total plug load equipment captured in this study. Perhaps the most telling variable is energy use intensity, which is estimated to be $10.19 \mathrm{kWh} / \mathrm{ft}^{2} /$ year in lab buildings, while office buildings are projected to use less than half of that at $4.72 \mathrm{kWh} / \mathrm{ft}^{2} /$ year. Estimated energy use intensity for all building types by equipment category is summarized in Fig. 8.

Table 4 Equipment quantity and energy consumption estimates by building type

\begin{tabular}{|c|c|c|c|c|c|c|}
\hline Building type & $\begin{array}{l}\text { Total } \\
\text { equipment } \\
\text { count }\end{array}$ & $\begin{array}{l}\text { Total } \\
\text { electricity use } \\
\text { (kWh/year) }\end{array}$ & $\begin{array}{l}\text { Average plug load } \\
\text { electricity use as } \\
\text { percent of total } \\
\text { building type } \\
\text { electricity use }\end{array}$ & $\begin{array}{l}\text { Plug load electricity } \\
\text { use as \% of total plug } \\
\text { load electricity use in } \\
\text { inventoried buildings }\end{array}$ & $\begin{array}{l}\text { Average plug } \\
\text { load energy } \\
\text { use intensity } \\
\left(\mathrm{kWh} / \mathrm{ft}^{2} / \text { year }\right)\end{array}$ & $\begin{array}{l}\text { Average plug } \\
\text { load power } \\
\text { density }\left(\mathrm{W} / \mathrm{ft}^{2}\right)\end{array}$ \\
\hline Labs & 56,110 & $33,189,649$ & $36 \%$ & $69 \%$ & 10.19 & 1.16 \\
\hline Offices & 27,900 & $9,473,215$ & $39 \%$ & $20 \%$ & 4.72 & 0.54 \\
\hline Classroom & 15,618 & $3,084,001$ & $31 \%$ & $6 \%$ & 1.84 & 0.21 \\
\hline Public space & 7273 & $1,344,297$ & $13 \%$ & $3 \%$ & 1.06 & 0.12 \\
\hline Rec facility & 2714 & 880,505 & $11 \%$ & $2 \%$ & 1.46 & 0.17 \\
\hline Service facility & 905 & 234,189 & $24 \%$ & $0 \%$ & 2.68 & 0.31 \\
\hline
\end{tabular}




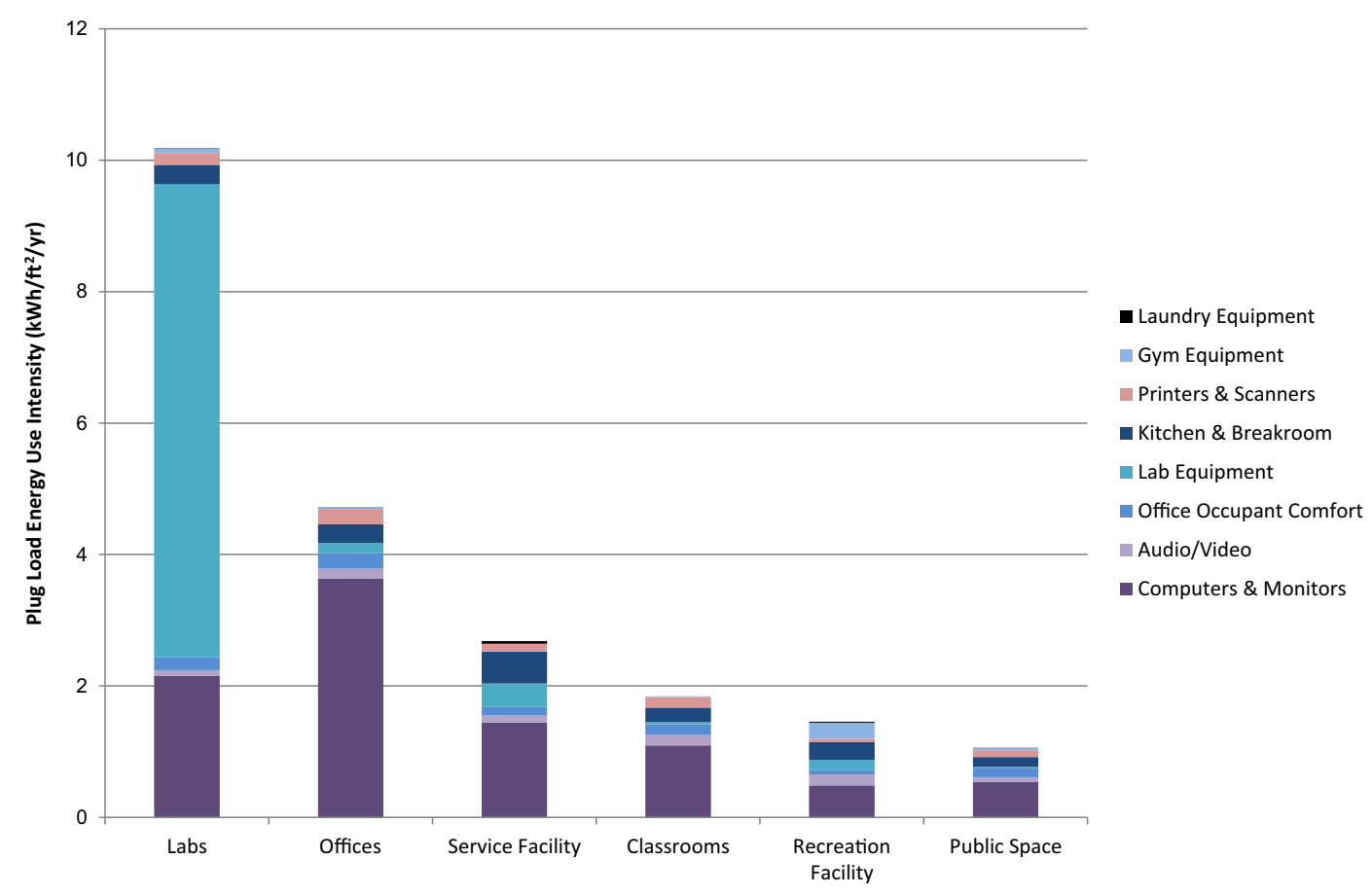

Fig. 8 Energy use intensity by building type and equipment category

This study also allowed Stanford to estimate the average plug load power density of its buildings, which was calculated by aggregating estimated annual building-level plug load energy consumption and converting to units of power, which provides an estimate for average power density per building but of course cannot be used to determine peak power density. As a whole, Stanford's average power density is estimated to be $0.62 \mathrm{~W} / \mathrm{ft}^{2}$, with significant variation by building type. On average, lab buildings have an estimated power density of $1.16 \mathrm{~W} / \mathrm{ft}^{2}$, while office buildings are projected to use $0.56 \mathrm{~W} / \mathrm{ft}^{2}$. On the low end of the spectrum, plug loads in public spaces consumed an estimated $0.12 \mathrm{~W} / \mathrm{ft}^{2}$.

One important note is that this study more fully captured data on equipment in office buildings, since a high percentage of office equipment can be categorized into the 55 equipment types included in this study. Thus, estimated plug load power density in this study can be estimated more accurately for office buildings than for lab buildings. In fact, the estimated plug load power density for office buildings in this study aligned well with measured plug load power density figures from Stanford's submetered office buildings, as illustrated in Table 5. While it is important to note that this study only takes average power density into account and cannot determine peak plug load power draw, this study has further substantiated the case built by Sheppy et al. (2014) that electrical infrastructure and cooling systems in office buildings are often oversized due to overestimated plug loads.

Finally, low numbers of ENERGY STAR-certified equipment were found across building types, so it does not appear that any one sector places more preference on purchasing ENERGY STAR-certified equipment than another. Of all equipment on campus for which the ENERGY STAR-certified attribute was recorded, only $16 \%$ contained the ENERGY STAR logo. In offices, this figure is $17 \%$, in labs it is $15 \%$, and in classrooms it is $12 \%$. While it is possible that some equipment was ENERGY STAR-certified but did not have a visible logo or that some equipment was ENERGY STAR-certified but ENERGY STAR was not collected as an attribute, this overall number is lower than expected and represents a significant opportunity for improvement in purchasing habits.

\section{Sensitivity}

The electricity consumption estimates listed throughout this paper are entirely dependent on assumptions regarding power draw and time spent in various power states, as discussed in the "Data analysis and methodology" section. Inherent in using assumptions to develop estimates is a level of uncertainty. To quantify and address 
Table 5 Comparison of measured (Sheppy et al. 2014) and calculated plug load power densities in Stanford office buildings

\begin{tabular}{|c|c|c|c|c|c|}
\hline Building & $\begin{array}{l}\text { Gross square } \\
\text { feet }\end{array}$ & $\begin{array}{l}\text { Estimated plug load energy use } \\
\text { (kWh/year) }\end{array}$ & $\begin{array}{l}\text { Measured average } \\
\mathrm{W} / \mathrm{ft}^{2}\end{array}$ & $\begin{array}{l}\text { Measured peak } \\
\mathrm{W} / \mathrm{ft}^{2}\end{array}$ & $\begin{array}{l}\text { Calculated } \\
\mathrm{W} / \mathrm{ft}^{2}\end{array}$ \\
\hline Office building 1 & 115,110 & 249,598 & 0.23 & 0.41 & 0.25 \\
\hline Office building 2 & 49,360 & 45,736 & 0.3 & 0.64 & 0.11 \\
\hline Office building 3 & 83,130 & 151,535 & 0.16 & 0.42 & 0.21 \\
\hline Office building 4 & 26,326 & 55,295 & 0.4 & 1.08 & 0.24 \\
\hline $\begin{array}{l}\text { Office buildings } 5 \text {, } \\
\quad 6,7\end{array}$ & 113,644 & 134,860 & 0.28 & 0.63 & 0.14 \\
\hline
\end{tabular}

the level of uncertainty in this study, a sensitivity analysis was performed. To determine the sensitivity of the energy consumption and savings estimates, key inputs were adjusted to determine minimum and maximum estimates for both energy consumption and savings. For consumption, assumptions were adjusted for every type of equipment by attribute. Overall, by applying minimum and maximum estimates, the plug load electricity consumption captured in this study could range from 17 to $57 \%$ of the energy consumption of the 220 buildings included in this study.

\section{Conclusion}

This study was designed to comprehensively collect data on the types and quantities of equipment that are present on Stanford's campus and to use that data to better understand the breakdown of plug load energy consumption and inform future work on viable plug load energy reduction strategies. Specifically, the plug loads collected and analyzed in this study were estimated to comprise $32 \%$ of the total energy consumption of the 220 buildings included in the inventory, with lab equipment consuming the highest portion of electricity and computers and monitors as the most prevalent types of equipment on campus. The findings from this study will be complimented by future research into equipment operating patterns and actual energy consumption to make energy consumption estimates more precise and by comparing and contrasting the potential savings strategies introduced in this study to determine their relative effectiveness.

The findings of this study suggest potential savings opportunities in the following categories: energy efficiency strategies in laboratories, such as reducing the energy use associated with ultra-low temperature freezers and turning lab equipment off when not in use; energy efficiency strategies for information technology, such as server virtualization and computer power management, off-the-shelf energy efficiency technologies, such as advanced power strips and programmable timers; condensing shared devices, such as printers; phasing out devices with redundant functionality, such as fax machines and scanners; and improving the energy efficiency of specific equipment types, such as specific energy efficiency measures for vending machines and increasing the saturation of all types of ENERGY STAR-certified equipment. These are just some of the abundance of potential strategies for reducing plug load energy consumption, but the data presented in this study regarding both the most prevalent types of devices and the devices with the highest energy consumption indicate that these may be some of the most effective. While much of the research cited in this study has focused on the evaluation of plug load energy savings strategies, there is certainly an opportunity for future work to compare and contrast the efficacy and feasibility of each of these strategies not only on a university campus but also in other commercial office and healthcare buildings, among others.

Additionally, many of the plug load reduction strategies suggested in this study rely on changes to human behavior. There would be significant value in developing a better understanding of how best to bring about sustained behavior change. Studies of behavior programs to date have shown varying results. For instance, Acker et al. (2012) found that regular emails to occupants reduced plug load draw during unoccupied hours by $4 \%$, but Murtagh et al. (2013) found that while behavior campaigns did result in immediate savings, the savings could not be sustained over time. More robust data on the effectiveness of various types of behavior change strategies would be invaluable in formulating effective plug load energy reduction programs across sectors. 
While this study captured a large range of equipment types and building types, it still does not holistically show Stanford's total plug load electricity consumption, and future work could focus on completing this picture. For instance, on-campus residences should be inventoried in order to fully capture the number of computers, printers, personal refrigerators, desk lamps, and other relevant plug load equipment types on campus, although these loads are subject to change more rapidly than other loads due to the transient student population. Future work could also focus on developing a better understanding of how much aggregate loads in student residences truly fluctuate year to year.

Additionally, it is likely that lab loads and IT loads are underrepresented due to the need to exclude certain sensitive buildings. For instance, Stanford's two largest data centers were not inventoried for security reasons, and several School of Medicine buildings were not inventoried to maintain patient privacy. Furthermore, the exclusion of specialized equipment means that a higher proportion of lab and IT equipment, which tends to be more specialized, may not have been recorded in the inventory compared to office equipment. Because of the large UEC of both lab equipment and IT equipment, the equipment not captured in this study could represent a significant portion of Stanford's plug load electricity consumption, and developing an even more comprehensive understanding of this equipment should be a priority.

On the other hand, the bottom-up strategy employed in this study aligned well with submetered plug load data, suggesting that surveys can be good indicators for plug load energy consumption. However, measured energy consumption data has the highest accuracy, and in fact, building codes like California's Title 24, which now requires building submetering, are already helping to achieve this. Several previous studies have included equipment metering at the outlet, but additional testing of this equipment, especially regarding the equipment's operation on a university campus, would be beneficial. Moreover, the large amount of effort required to attach a meter to every piece of equipment included in plug load studies severely limits the scale of the studies. As metering technology improves in this regard, more equipment can be included in these studies, and energy consumption patterns of various types of plug load equipment on a larger scale across multiple building types can more easily be tested.

More advanced load disaggregation technologies also have the potential to facilitate plug load data collection. As load disaggregation technologies develop to be able to identify the specific signatures of various appliances and other types of plug load equipment, those services can be used to predict what type of equipment is being used in a building and when, without having to conduct physical building surveys. Stanford's equipment inventory provides a baseline with which this data can be compared in the future. However, because this study only captured a snapshot in time of the equipment on Stanford's campus, there is currently no mechanism built in to this study for tracking changes over time. While some prior studies have included multiple building surveys, they have primarily done so in order to track seasonal changes in the presence of various types of equipment, such as Acker et al. (2012). However, to our knowledge, robust surveys have not been conducted to date to track equipment presence and/or operation over time. This information would be extremely informative so that organizations could predict trends in their long-term plug load energy consumption patterns.

As plug loads continue to increase as a percentage of energy consumption in buildings, it will become increasingly more important to understand how to effectively manage them, especially in reducing the wasted energy associated with plug loads. The results of this study can inform energy reduction opportunities not only on other university campuses but also within other types of commercial buildings, especially office and healthcare facilities. Although there are certain traits, such as varied populations of faculty, staff, and students, that make university campuses unique, the aggregated data from this comprehensive study should smooth over any data from outlier buildings that may have unusual populations or schedules, making it more relevant to the entire commercial sector. Data from this study should especially be used to inform the types and energy consumption of equipment that can be found in healthcare facilities, as less research is currently available on the equipment in those spaces. While the data collected in this study may not holistically represent the plug load profiles of all types of healthcare facilities, it can provide a baseline that can be used by healthcare facilities to better understand the plug load profiles in their spaces. Ideally, future studies will combine with developing technologies within all three of these sectors to continue to make it easier to measure, track, and reduce plug loads over time. In the meantime, building surveysthough they involve significant effort-are an effective method for collecting plug load data at a granular level 
and can continue to inform the constantly changing realm of plug loads across multiple building types.

Acknowledgments Many thanks to several groups within Stanford University's Land, Buildings \& Real Estate (LBRE) division: Jack Cleary and Joe Stagner for their executive leadership in the Department of Sustainability and Energy Management (SEM) and their support of this study; Fahmida Ahmed for guidance and oversight of the study; Swati Prabhu, Wilson Lee, Totran Mai, Chris Cheng, and Supriya Bhagwat in the LBRE Applications Systems group for designing the smartphone/tablet application used for data collection; and the Department of Building and Grounds Maintenance (BGM) for guidance and access to building managers who were vital to the success of the inventory. I am also grateful to my content contributors and reviewers: Rashmi Sahai, Leslie Kramer, Scott Gould, Raymond Pierson, and Andrew Gong. Finally, this study could not have been completed without dedicated student interns. I owe my thanks to the following: Temesgen Adumer, Victoria Brumbaugh, Taylor Burdge, Raul Cabrera, Benjamin Churnside, Naomi Cornman, Pauline Hanset, KJ Lee, Alicia Menendez, Andrew Misiolek, Davianna Olert, Raymond Pierson, John Ribeiro-Broomhead, Jovinson Ripert, Dylan Sarkisian, and Darel Scott. These are all Stanford students or former Stanford students who contributed to data collection and/or analysis for this study.

\section{Compliance with ethical standards}

Funding This study was funded by Stanford University through the Department of Sustainability and Energy Management.

Conflict of interest Moira Hafer is employed by Stanford University as a Sustainability Specialist in the Department of Sustainability and Energy Management.

Open Access This article is distributed under the terms of the Creative Commons Attribution 4.0 International License (http:// creativecommons.org/licenses/by/4.0/), which permits unrestricted use, distribution, and reproduction in any medium, provided you give appropriate credit to the original author(s) and the source, provide a link to the Creative Commons license, and indicate if changes were made.

\section{Appendix}

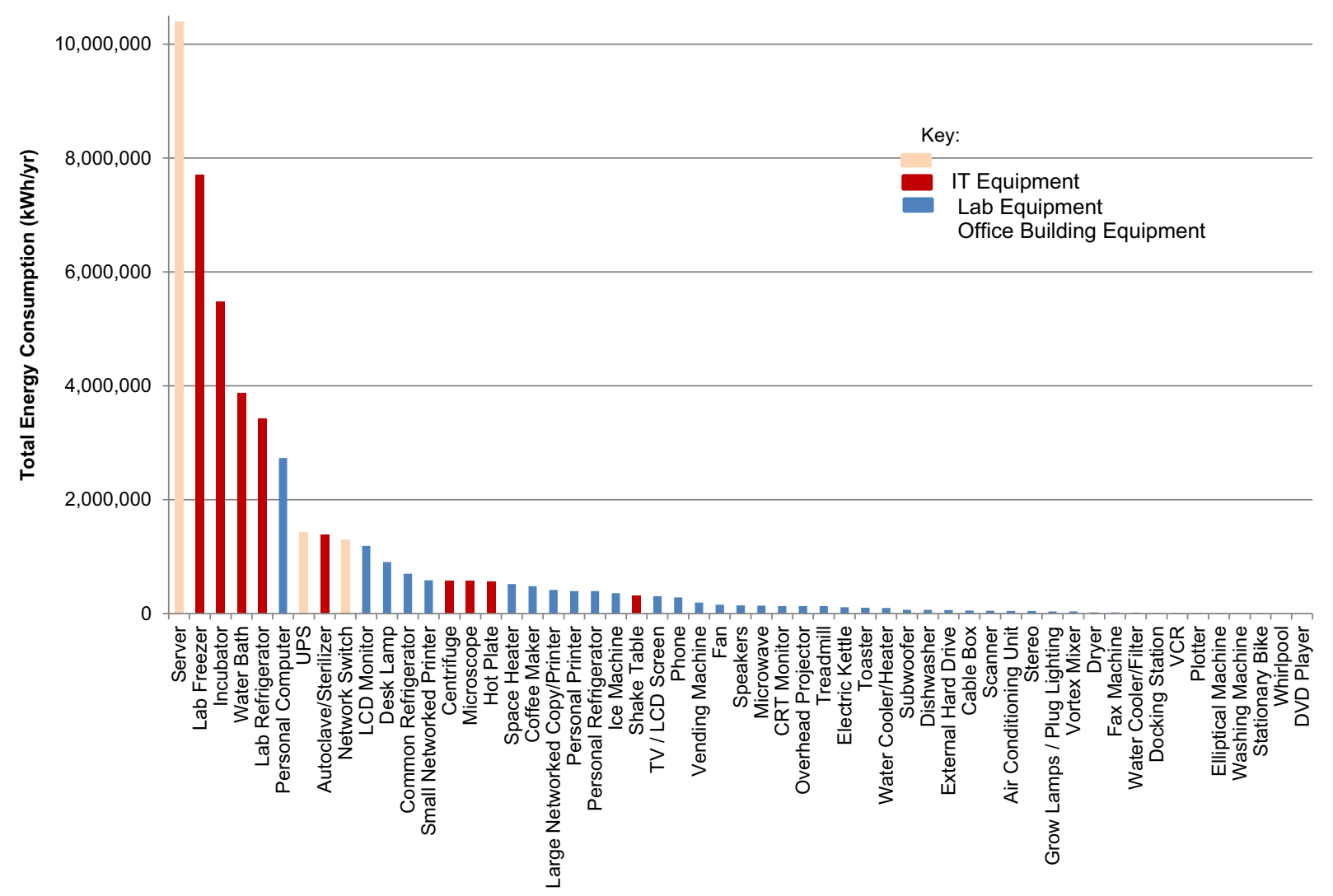

Fig. 9 Total equipment energy consumption (kWh/year) 


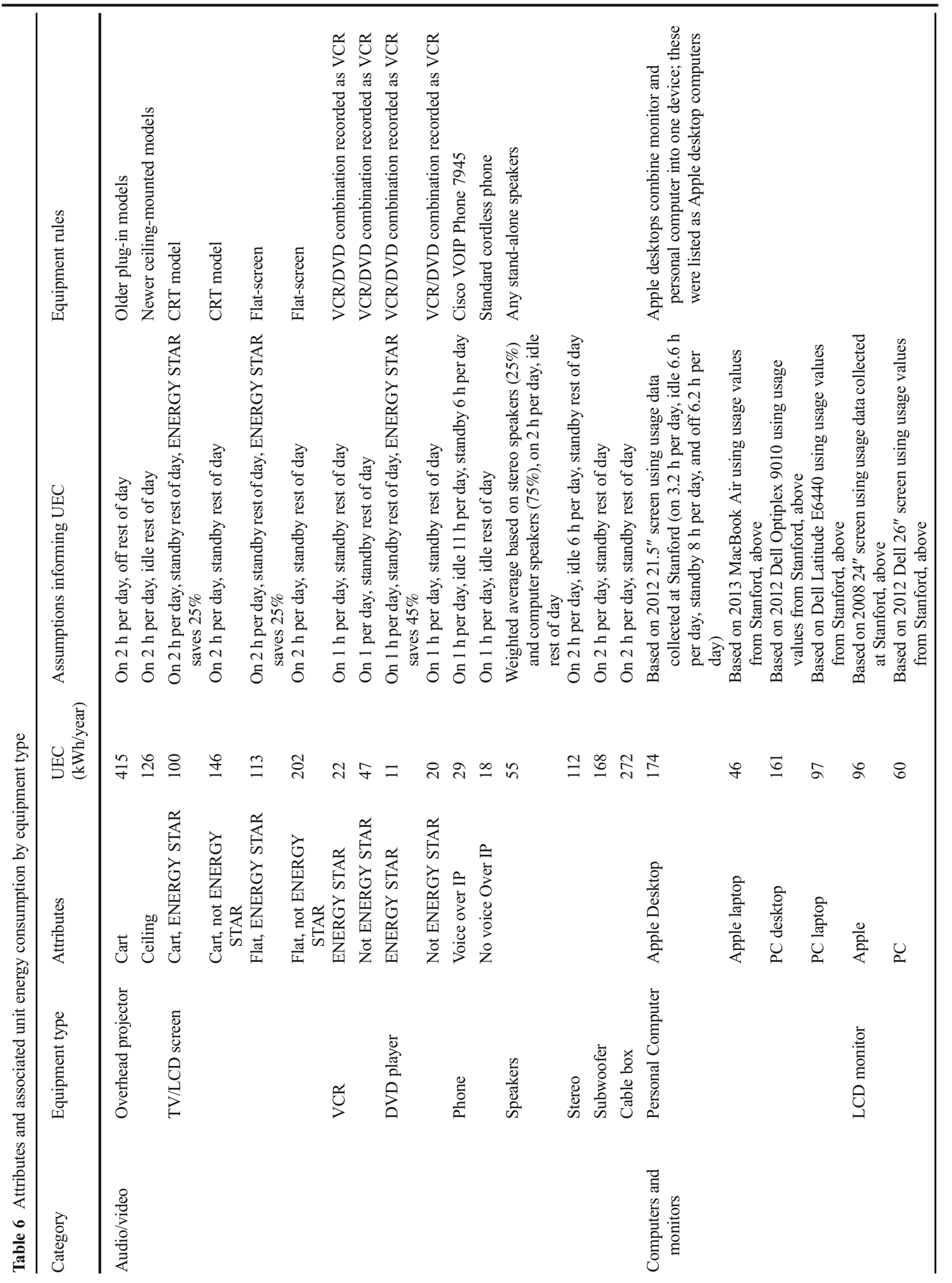




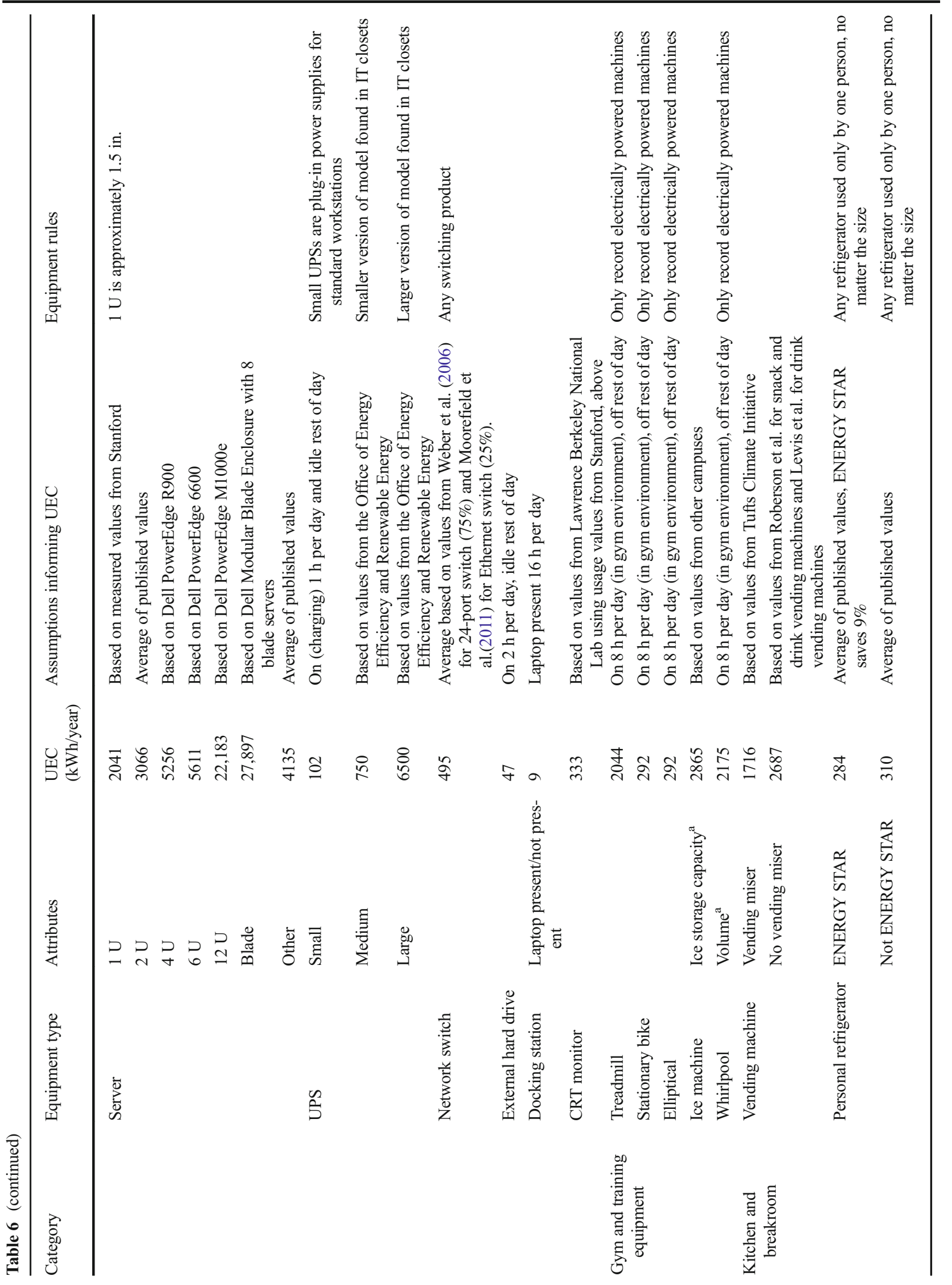




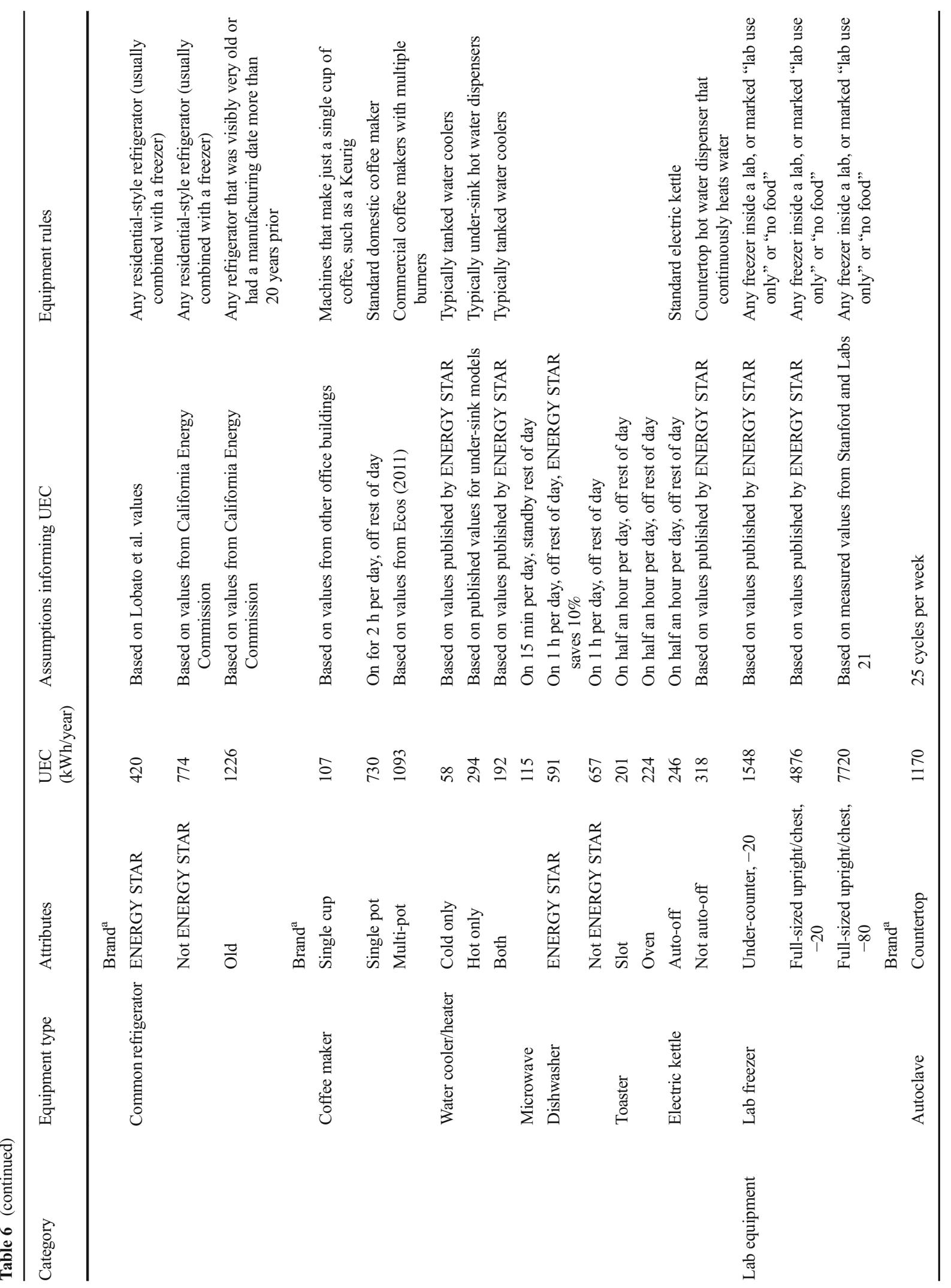




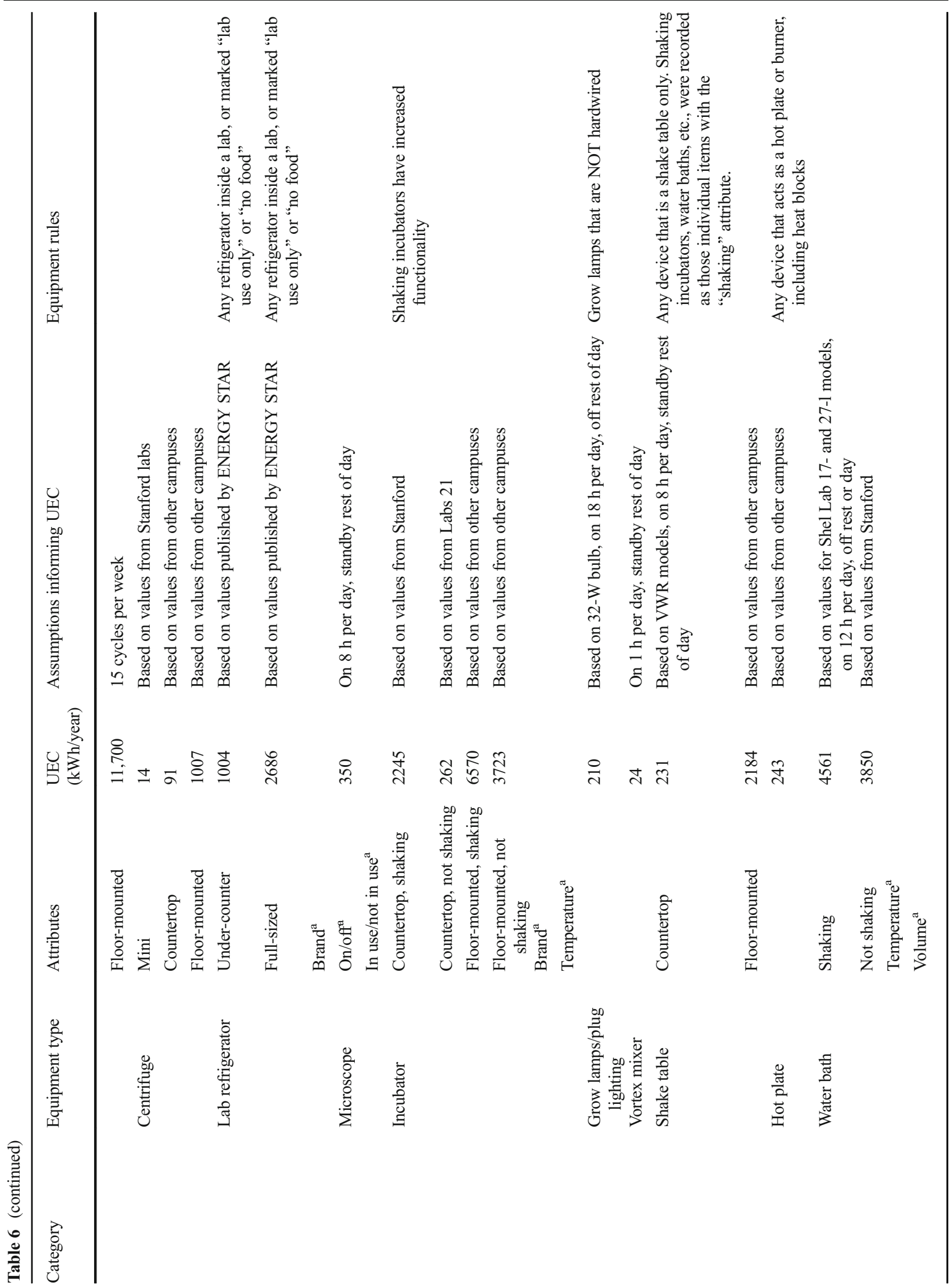




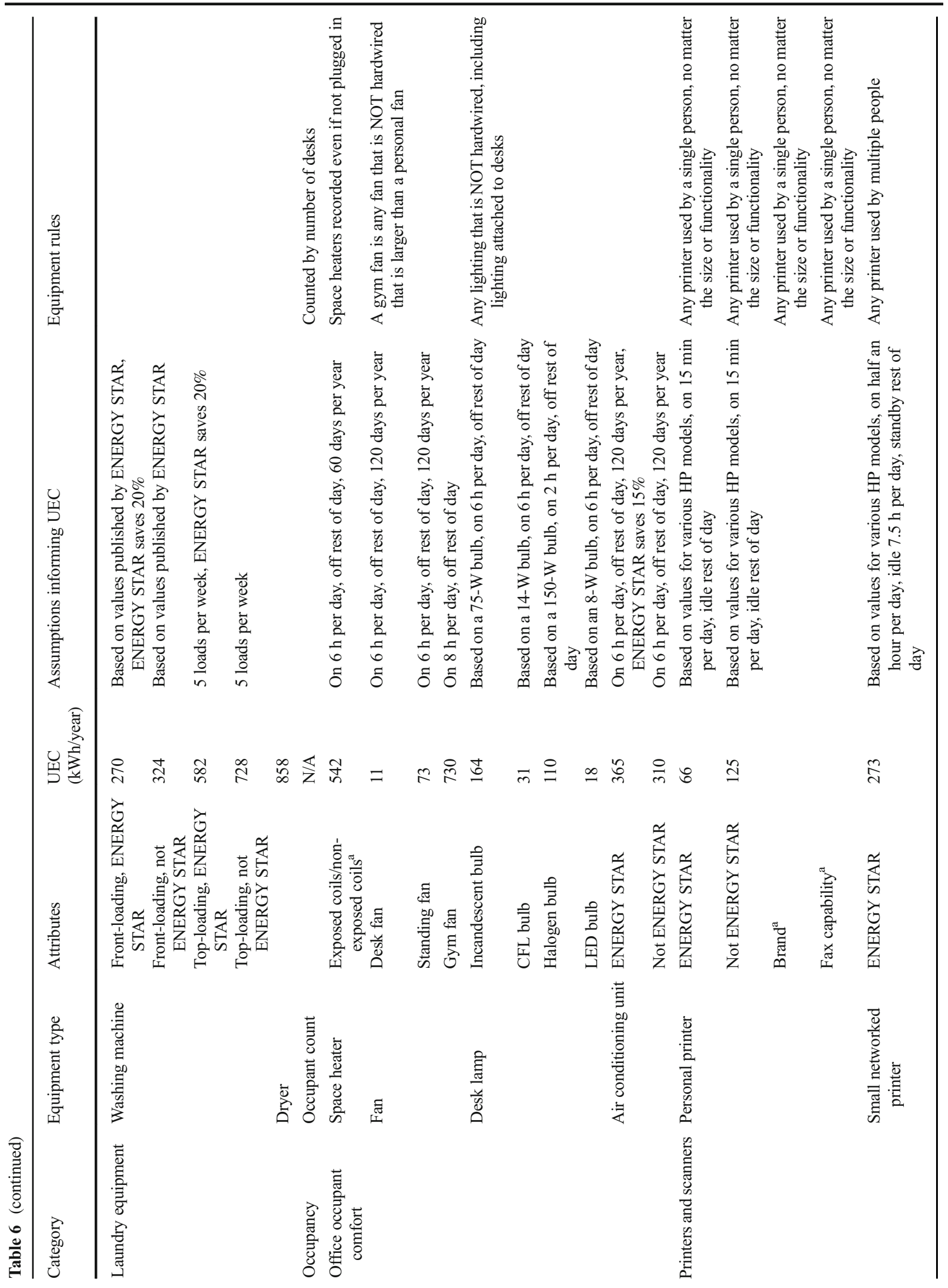




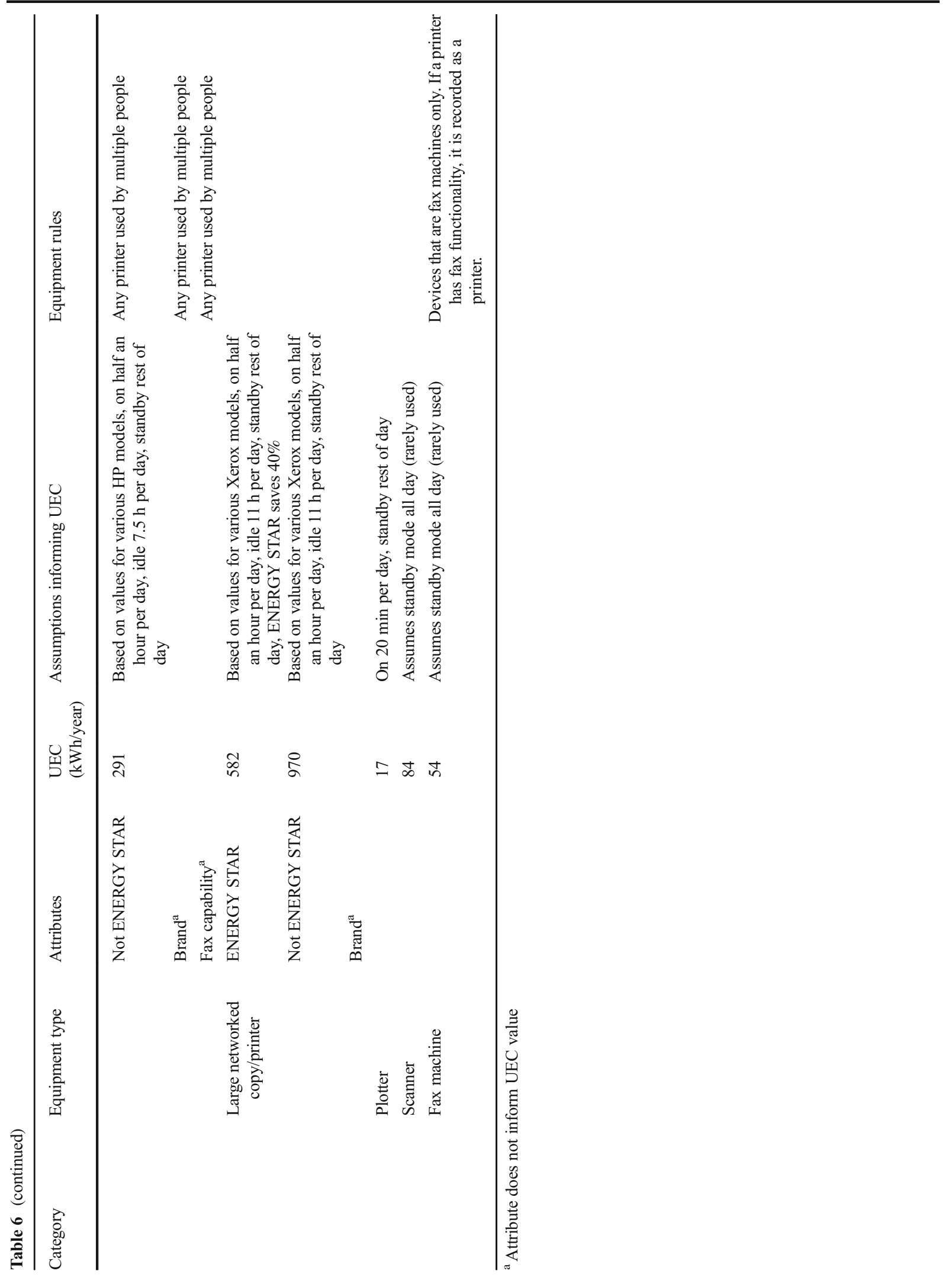


Table 7 Equipment count, energy consumption and density by equipment type

\begin{tabular}{|c|c|c|c|c|c|c|c|}
\hline Category & Equipment type & $\begin{array}{l}\text { Total } \\
\text { count }\end{array}$ & $\begin{array}{l}\% \text { Count of } \\
\text { total equipment }\end{array}$ & $\begin{array}{l}\text { TEC } \\
(\mathrm{kWh} / \text { year })\end{array}$ & $\begin{array}{l}\% \text { Energy used of } \\
\text { total plug loads }\end{array}$ & $\begin{array}{l}\text { Density (units per } \\
\text { thousand square feet) }\end{array}$ & $\begin{array}{l}\text { Density (units } \\
\text { per occupant) }\end{array}$ \\
\hline \multirow[t]{9}{*}{ Audio/video } & TV/LCD screen & 1734 & $1.57 \%$ & 303,695 & $0.63 \%$ & 0.19 & 0.10 \\
\hline & Phone & 10,485 & $9.49 \%$ & 284,276 & $0.59 \%$ & 1.18 & 0.63 \\
\hline & Speakers & 2620 & $2.37 \%$ & 143,786 & $0.30 \%$ & 0.29 & 0.16 \\
\hline & Overhead projector & 759 & $0.69 \%$ & 133,025 & $0.28 \%$ & 0.09 & 0.05 \\
\hline & Subwoofer & 398 & $0.36 \%$ & 66,824 & $0.14 \%$ & 0.04 & 0.02 \\
\hline & Cable box & 194 & $0.18 \%$ & 52,824 & $0.11 \%$ & 0.02 & 0.01 \\
\hline & Stereo & 398 & $0.36 \%$ & 44,743 & $0.09 \%$ & 0.04 & 0.02 \\
\hline & VCR & 257 & $0.23 \%$ & 10,885 & $0.02 \%$ & 0.03 & 0.02 \\
\hline & DVD Player & 325 & $0.29 \%$ & 6188 & $0.01 \%$ & 0.04 & 0.02 \\
\hline \multirow{8}{*}{$\begin{array}{l}\text { Computers and } \\
\text { monitors }\end{array}$} & Server & 2049 & $1.85 \%$ & $10,399,486$ & $21.57 \%$ & 0.23 & 0.12 \\
\hline & Personal computer & 20,117 & $18.20 \%$ & $2,733,398$ & $5.67 \%$ & 2.26 & 1.21 \\
\hline & UPS & 1416 & $1.28 \%$ & $1,428,493$ & $2.96 \%$ & 0.16 & 0.09 \\
\hline & Network switch & 2631 & $2.38 \%$ & $1,302,345$ & $2.70 \%$ & 0.30 & 0.16 \\
\hline & LCD monitor & 18,803 & $17.01 \%$ & $1,189,455$ & $2.47 \%$ & 2.11 & 1.13 \\
\hline & CRT monitor & 402 & $0.36 \%$ & 133,719 & $0.28 \%$ & 0.05 & 0.02 \\
\hline & External hard drive & 1326 & $1.20 \%$ & 62,919 & $0.13 \%$ & 0.15 & 0.08 \\
\hline & Docking station & 1368 & $1.24 \%$ & 11,984 & $0.02 \%$ & 0.15 & 0.08 \\
\hline \multirow{5}{*}{$\begin{array}{l}\text { Gym and } \\
\text { training } \\
\text { equipment }\end{array}$} & Ice machine & 125 & $0.11 \%$ & 358,125 & $0.74 \%$ & 0.01 & 0.01 \\
\hline & Treadmill & 64 & $0.06 \%$ & 130,816 & $0.27 \%$ & 0.01 & 0.00 \\
\hline & Elliptical machine & 50 & $0.05 \%$ & 8760 & $0.02 \%$ & 0.01 & 0.00 \\
\hline & Stationary bike & 23 & $0.02 \%$ & 6716 & $0.01 \%$ & 0.00 & 0.00 \\
\hline & Whirlpool & 3 & $0.00 \%$ & 6526 & $0.01 \%$ & 0.00 & 0.00 \\
\hline \multirow{10}{*}{$\begin{array}{l}\text { Kitchen and } \\
\text { breakroom }\end{array}$} & Common refrigerator & 919 & $0.83 \%$ & 699,611 & $1.45 \%$ & 0.10 & 0.06 \\
\hline & Coffee maker & 1022 & $0.92 \%$ & 482,865 & $1.00 \%$ & 0.11 & 0.06 \\
\hline & Personal refrigerator & 1277 & $1.16 \%$ & 393,686 & $0.82 \%$ & 0.14 & 0.08 \\
\hline & Vending machine & 81 & $0.07 \%$ & 192,374 & $0.40 \%$ & 0.01 & 0.00 \\
\hline & Microwave & 1221 & $1.10 \%$ & 140,861 & $0.29 \%$ & 0.14 & 0.07 \\
\hline & Electric kettle & 427 & $0.39 \%$ & 113,280 & $0.23 \%$ & 0.05 & 0.03 \\
\hline & Toaster & 476 & $0.43 \%$ & 101,557 & $0.21 \%$ & 0.05 & 0.03 \\
\hline & Water cooler/heater & 486 & $0.44 \%$ & 98,785 & $0.20 \%$ & 0.05 & 0.03 \\
\hline & Dishwasher & 102 & $0.09 \%$ & 66,324 & $0.14 \%$ & 0.01 & 0.01 \\
\hline & Water cooler/filter & 79 & $0.07 \%$ & 17,467 & $0.04 \%$ & 0.01 & 0.00 \\
\hline \multirow[t]{11}{*}{ Lab equipment } & Lab freezer & 1520 & $1.38 \%$ & $7,705,669$ & $15.98 \%$ & 0.17 & 0.09 \\
\hline & Incubator & 1600 & $1.45 \%$ & $5,483,235$ & $11.37 \%$ & 0.18 & 0.10 \\
\hline & Water bath & 986 & $0.89 \%$ & $3,864,514$ & $8.02 \%$ & 0.11 & 0.06 \\
\hline & Lab refrigerator & 1759 & $1.59 \%$ & $3,417,959$ & $7.09 \%$ & 0.20 & 0.11 \\
\hline & Autoclave/sterilizer & 167 & $0.15 \%$ & $1,385,280$ & $2.87 \%$ & 0.02 & 0.01 \\
\hline & Centrifuge & 2746 & $2.48 \%$ & 579,185 & $1.20 \%$ & 0.31 & 0.16 \\
\hline & Microscope & 1649 & $1.49 \%$ & 577,810 & $1.20 \%$ & 0.19 & 0.10 \\
\hline & Hot plate & 2273 & $2.06 \%$ & 552,378 & $1.15 \%$ & 0.26 & 0.14 \\
\hline & Shake table & 644 & $0.58 \%$ & 312,637 & $0.65 \%$ & 0.07 & 0.04 \\
\hline & $\begin{array}{l}\text { Grow lamps/plug } \\
\text { lighting }\end{array}$ & 185 & $0.17 \%$ & 38,894 & $0.08 \%$ & 0.02 & 0.01 \\
\hline & Vortex mixer & 1593 & $1.44 \%$ & 38,085 & $0.08 \%$ & 0.18 & 0.10 \\
\hline
\end{tabular}


Table 7 (continued)

\begin{tabular}{|c|c|c|c|c|c|c|c|}
\hline Category & Equipment type & $\begin{array}{l}\text { Total } \\
\text { count }\end{array}$ & $\begin{array}{l}\% \text { Count of } \\
\text { total equipment }\end{array}$ & $\begin{array}{l}\text { TEC } \\
(\mathrm{kWh} / \text { year) }\end{array}$ & $\begin{array}{l}\% \text { Energy used of } \\
\text { total plug loads }\end{array}$ & $\begin{array}{l}\text { Density (units per } \\
\text { thousand square feet) }\end{array}$ & $\begin{array}{l}\text { Density (units } \\
\text { per occupant) }\end{array}$ \\
\hline \multirow{6}{*}{$\begin{array}{l}\text { Office } \\
\text { occupant } \\
\text { comfort }\end{array}$} & Dryer & 25 & $0.02 \%$ & 21,450 & $0.04 \%$ & 0.00 & 0.00 \\
\hline & Washing machine & 19 & $0.02 \%$ & 7421 & $0.02 \%$ & 0.00 & 0.00 \\
\hline & Desk Lamp & 13,563 & $12.27 \%$ & 904,332 & $1.88 \%$ & 1.52 & 0.81 \\
\hline & Space heater & 955 & $0.86 \%$ & 517,634 & $1.07 \%$ & 0.11 & 0.06 \\
\hline & Fan & 1865 & $1.69 \%$ & 156,085 & $0.32 \%$ & 0.21 & 0.11 \\
\hline & Air conditioning unit & 151 & $0.14 \%$ & 47,368 & $0.10 \%$ & 0.02 & 0.01 \\
\hline \multirow[t]{6}{*}{$\begin{array}{c}\text { Printers and } \\
\text { scanners }\end{array}$} & $\begin{array}{l}\text { Small networked } \\
\text { printer }\end{array}$ & 2037 & $1.84 \%$ & 583,658 & $1.21 \%$ & 0.23 & 0.12 \\
\hline & $\begin{array}{l}\text { Large networked } \\
\text { copy/printer }\end{array}$ & 520 & $0.47 \%$ & 415,314 & $0.86 \%$ & 0.06 & 0.03 \\
\hline & Personal printer & 3582 & $3.24 \%$ & 397,433 & $0.82 \%$ & 0.40 & 0.22 \\
\hline & Scanner & 614 & $0.56 \%$ & 51,635 & $0.11 \%$ & 0.07 & 0.04 \\
\hline & Fax machine & 378 & $0.34 \%$ & 20,397 & $0.04 \%$ & 0.04 & 0.02 \\
\hline & Plotter & 61 & $0.06 \%$ & 9919 & $0.02 \%$ & 0.01 & 0.00 \\
\hline
\end{tabular}

\section{References}

Acker, B., Duarte, C. \& Van Den Wymelenenberg, K. (2012). Office building plug load profiles. Technical report 20100312-01. Integrated Design Lab, University of Idaho, Boise, ID. h t t p : / / w w w a d va n c e d b u i $1 \mathrm{~d}$ i n g s. net/files/advancebuilding s/20100312-01 OfficePlugLoads_20120524.pdf. Accessed 16 March 2015.

Black, D., Lanzisera, S., Lai, J., Brown, R. \& Singer, B. (2012). Evaluation of miscellaneous and electronic device energy use in hospitals. Lawrence Berkeley National Laboratory. Report number: LBNL-6084E. Accessed 18 August 2016.

Energy Information Administration. (2014). Annual energy outlook 2014 with projections to 2040. Resource document. Retrieved from http://www.eia.gov/forecasts/aeo/pdf/0383 (2014).pdf. Accessed 23 February 2015.

Kamilaris, A., Kalluri, B., Kondepudi, S., \& Kwok Wai, T. (2013). A literature survey on measuring energy usage for miscellaneous electric loads in offices and commercial buildings. Renewable and Sustainable Energy Reviews, 34, 536-550.

Kawamoto, K., Koomey, J., Nordman, B., Brown, R., Piette, M., Ting, M., \& Meier, A. (2002). Electricity used by office equipment and network equipment in the US. Energy, 27, 255-269.

Lanzisera, S., Dawson-Haggerty, S., Cheung, H. Y., Taneja, J., Culler, D., \& Brown, R. (2013). Methods for detailed energy data collection of miscellaneous and electronic loads in a commercial building. Building and Environment, 65, 170-177.

Lanzisera, S., Nordman, B., \& Brown, R. (2012). Data network equipment energy use and savings potential in buildings. Energy Efficiency, 5, 149-162.

Lewis, K., Shaw, S., Korn, D. \& Banas, S. (2006). Serving up savings: the new value equation for energy efficient vending machines. ACEEE Summer Study on Energy Efficiency in Buildings, 2006. American Council for an Energy Efficient Economy. Conference Paper. http://www.eceee.org/library/conference
proceedings/ACEEE_buildings/2006/Panel_4/p4_18/paper. Accessed 16 March 2015.

Lobato, C., Pless, S., Sheppy, M \& Torcellini, P. (2011). Reducing plug and process loads for a large scale, low energy office building: NREL's research support facility. 2011 ASHRAE Winter Conference, Las Vegas, NV, January 29, 2011February 2, 2011. American Society of Heating, Refrigerating and Air Conditioning Engineers, 2011. Conference Paper NREL/CP-5500-49002. http:/www.nrel.gov/sustainable nrel/pdfs/49002.pdf. Retrieved 23 February 2015.

Moorefield, L., Frazer, B. \& Bendt, P. 2011. Office plug load field monitoring report. California Energy Commission, PIER Energy-Related Environmental Research Program. PIER Final Project Report CEC-500-2011-010. http://www. energy.ca.gov/2011publications/CEC-500-2011-010/CEC500-2011-010.pdf. Accessed 23 February 2015.

Murtagh, N., Nati, M., Headley, W., Gaterslelben, B., Gluhak, A., Imran, M., \& Uzzell, D. (2013). Individual energy use and feedback in an office setting: a field trial. Energy Policy, 62, 717-728.

Nordman, B. \& Sanchez, M. (2006). "Electronics come of age: a taxonomy for miscellaneous and low power products." Resource document. Lawrence Berkeley National Laboratory. http://nordman.lbl.gov/docs/taxonomy.pdf. Accessed 16 March 2015.

Pixley, J. \& Ross, S. (2014). Monitoring Computer Power Modes Usage in a University Population. California Energy Commission. Publication number: CEC-500-2014-092.

Sheppy, M., Gentile-Polese, L. \& Gould, S. (2014). Plug and process loads capacity and power requirements analysis. Energy Efficiency \& Renewable Energy Office, U.S. Department of Energy. Resource document. http://www.nrel.gov/docs/fy14 osti/60266.pdf. Accessed 6 November 2014.

Webber, C., Roberson, J., McWhinney, M., Brown, R., Pinckard, M., \& Busch, J. (2006). After-hours power status of office equipment in the USA. Energy, 31, 2823-2838. 